October 24, 2016

\title{
Sources of Change in the Demand for Energy by Indonesian Households: 1980-2002
}

Abstract

This paper describes the energy transition in Indonesia and examines the determinants of energy demand, by fuel. The key innovation of this paper is the documentation of how these relationships have evolved over time. We present a new method to combine econometric analysis and index decomposition analysis to examine household energy transition. This approach also allows us to consider a broad range of demographic and structural factors, while providing a clear and concise representation of our findings. We find that the composite indices mask important underlying patterns. In particular, our results indicate that energy transition in Indonesia cannot be confidently attribute to any one index. Rather, it has been driven predominantly by the triple interaction of demographics, income growth, and change in demand/supply parameters. Our findings point to the importance of utilizing time-series data in studying both the characteristics and determinants of energy transition in developing countries.

JEL Codes: O13, O53, Q41, Q56

Keywords: energy transition; demography; Indonesia

\section{Acknowledgements}

The authors would like to thank Brian O'Neill and seminar participants at Brown University for many helpful comments. This research was supported by the Office of Science (BER), US Department of Energy, Grant No. DE-FG02-01ER63216. 


\section{Introduction}

The study of energy usage and fuel choice has become increasingly important and urgent as scientific research reveals the environmental impact of carbon emissions and the adverse effects of indoor air pollution. In particular, researchers and policymakers alike have turned their attention to developing countries as these populations become ever larger consumers of energy. Households are also thought to experience an "energy transition" or to move along an "energy ladder" (Leach, 1992; Barnes and Floor, 1999; Barnes and Qian, 1992; Hosier and Kipondya, 1993), whereby broader trends in economic development generate a shift in the fuel mix towards commercial fuels and away from biomass. But, as Jiang and O'Neill (2004) point out, the characteristics of this phenomenon have not been well-documented, and it is unclear whether the declining share of biomass energy represents a net reduction in absolute biomass use. Moreover, the existing literature has not adequately explored the relationship between energy transition and demographic transition. Static links between fuel choice and demographic characteristics have been well-documented, but the connection with demographic change remains much less clear. As the demographic transition often precedes economic development in today's developing countries, effective energy policy must take into account how demographic change within a population may influence both the timing and the path of the energy transition.

This paper has two main contributions. First, we describe trends in energy usage in Indonesia, in terms of both quantity and composition. Careful and detailed descriptions of energy use, over time, have been conducted for several countries but has not, to date, been conducted for Indonesia (Permana et. al., 2008, presents a case study of Bandung City, the capital of West Java province in Indonesia for a single point in time). We focus on the two decades in which Indonesia experienced its most significant economic expansion to date (1980-2002). This growth 
was precipitated by falling oil prices in the 1980s, which prompted the Indonesian government to diversify away from oil exports and towards manufactured exports, accelerating industrialization (Elias and Noone, 2013). Indonesia is now the fifth most populous country in the world with the $9^{\text {th }}$ largest economy, based on PPP-adjusted GDP. Between 1980 and 1997 (before the Asian Financial Crisis), Indonesia's GNI per capita experienced an annualized growth rate of $4.16 \%$. Indonesia is also ranked $23^{\text {rd }}$ in the world in crude oil production, and $25^{\text {th }}$ in crude oil exports, and the nation has even greater stores of natural gas, ranking at $12^{\text {th }}$ in both production and exports (CIA, 2016). This period also marks a dramatic shift in Indonesia's demographic transition. After reaching its peak in the early 1970s, the population growth rate began decreasing, with fertility falling by half, nearly to the replacement rate, by the turn of the century. Life expectancy increased from 58 to 65 , the population growth rate fell from $2 \%$ to $1 \%$, and primary school completion rates increased from $58 \%$ to $99 \%$. Urbanization also increased rapidly, from $22.1 \%$ in 1980 to $43.6 \%$ in 2002 (World Bank, 2012).

These features make Indonesia both a key component of world energy use and an instructive case for examining the relationship between fuel choice and demographic change. The relationships we estimate can provide insight into the energy transition for other countries at a similar point in the development process - that is, in the early stages of industrialization, urbanization, and demographic transition. Within this group, our findings may be particularly relevant for other oil-producing and/or resource-rich countries, such as Nigeria (McNicoll, 2011), given Indonesia's natural resources. However, Indonesia's growth during this time was due largely to industrialization rather than resource extraction, suggesting that our findings may apply more broadly. Additionally, as discussed below, our analysis allows us to disentangle and differentiate the impacts of demographic, economic, and structural change, so that we can 
consider the impact of, say, demographic change alone, without the accompanying economic and structural change observed in Indonesia during this period.

The second key contribution of this paper is to identify the determinants of the observed energy transition. We estimate the household demand for energy, disaggregated by type, accounting for a wide variety of demographic characteristics and allowing their influence on energy use to vary over time. Previous studies generally have two main limitations. First, those that have been able to obtain data over a longer time period tend to estimate a single average effect, held constant over time, and for only one factor at a time. Barnes et. al. (2005) find a clear positive relationship between household size and use of biomass, and vice versa for modern fuels, using data from the World Bank’s Energy Sector Management Assistance Programme (ESMAP). However, their calculations are done by stacking all years of data (1984-1999) together, which may mask important changes in this relationship over time and throughout the energy transition. Taking a historical perspective, Gales et. al. (2007) estimate that growth in per capita income accounted for $55 \%$ of the change in energy consumption in Sweden, the Netherlands, Italy and Spain between 1870 and 2000 but, again they do not allow the effect of income to vary over time.

Alternatively, there have been several papers to examine the effect of multiple factors, economic and demographic, simultaneously, but these rely on a single cross-section of data, precluding any analysis of how these relationships may have evolved over time. Jiang and O’Neill (2004) and Pachauri and Jiang (2008) examine a wide range of demographic characteristics (sex, education, and occupation of household head; household size and structure; geographic location) in addition to household income for China and India, utilizing a single cross-section of data in each case. Heltburg (2004) utilizes data from eight diverse countries and 
examines the relationships between fuel choice and income, household size and education. Again, the data are drawn from a single point in time, but it is evident that the estimated relationships, although generally consistent with an energy transition, differ substantially across countries in terms of not only magnitude but also sign. One exception is Campbell et. al. (2003), which utilizes data over a five year period (1994-1999) and does treat each time period separately. Their calculations suggest that rates of changes for electricity and kerosene use do not differ across income groups. They do not, however, document or account for the effect of other correlated demographic characteristics, which are likely to affect the observed relationship between income and fuel choice.

Another notable exception is the large literature on index decomposition analysis (IDA). The IDA methodology utilizes time-series data to separate changes in energy use into their component parts (e.g., sectoral/industrial composition, energy efficiency), generally by using observed shares/intensities (see Ang and Zhang, 2000 for an overview). More recently, this approach has been extended to consider changes in not only industrial energy use, but household energy demand as well. Nie and Kemp (2014) use the logarithmic mean Divisa index (LMDI, Ang et. al., 1998) to examine changes in household energy use in China between 2002 and 2010. Song and Zhen (2012) and Zhang (2013) utilize both IDA and econometric analysis to estimate the determinants of the energy transition in China and the transition economies of Eastern Europe and Central Asia, respectively. In this paper, we present a new method to combine econometric analysis and index decomposition analysis (IDA) to examine household energy transition. This approach also allows us to consider several different energy sources along with a very broad range of demographic and structural factors, while providing a clear and concise representation of our findings. 
We examine the share of the household fuel budget allocated to each type of fuel (including firewood, charcoal, kerosene, liquefied petroleum gas (LPG), city/natural gas, and electricity). We utilize a Tobit (Tobin, 1958) specification, which allows us to capture both the decision to use a particular fuel as well as the quantity that is ultimately consumed. Our data permit the estimation of energy demand equations that are flexible in a number of important dimensions. In particular, the estimated demand equations:

(1) incorporate detailed information on the demographic composition of households,

(2) allow the household response to income change to be very flexible,

(3) permit preferences for energy, by type, to change over time and independently of income and demographic changes,

(4) allow the effects of demographic change to vary with household income and household size,

(5) control for province-level unobserved heterogeneity in energy demand through the use of fixed effects, and

(6) identify the impact of the geographic distribution of the population, separate from the distribution between rural and urban areas, on energy demand.

Flexibility is obtained by allowing double and triple interactions between variables, and by allowing the full set of parameters to vary over time without restriction. The benefit of this approach is that it better captures the complex ways in which energy demand evolves over time in a rapidly changing developing country. The challenge is that individual regression parameters are not easily interpretable. For example, calculating the effect of a change in the number of household members on the demand for any particular type of energy requires evaluating an expression involving dozens of parameters and variables. Instead, we borrow methods from 
index decomposition analysis to summarize the effects of demographic change, income growth, and changes in preferences on the demand for various fuels in Indonesia between 1980 and 1999.

\section{Data and Context}

The data are drawn from the 1980, 1984, 1987, 1990, 1993, 1999 and 2002 Indonesian National Socioeconomic Surveys, commonly known by the acronym SUSENAS. The SUSENAS is a series of surveys initiated in 1963-1964 and conducted periodically by the national statistical agency, Biro Pusat Statistik (BPS). Although the initial rounds covered only selected provinces due to funding constraints, the sampling frame has been nationally representative throughout the 1990s. In 1993, the sample size was extended from 65,000 households to 202,000 households. Each survey consists of a core questionnaire to collect basic demographic data such as relationship to the household head, sex, age, marital status, and educational attainment of all household members. In 1992, the core questionnaire was extended to include critical indicators of individual and household welfare such as ownership of durable goods, roof/floor/wall construction, nutritional status, and labor force participation. Since 1990, the core questionnaire has been administered every year and accompanied by a detailed module. There are three modules which rotate from year to year: (1) income and expenditure; (2) socio-culture, tourism, welfare and crime; and (3) health, education, housing and sanitation.

Beginning in 1981, the income and expenditure data have been collected every three years; similar survey instruments were also implemented in 1976, 1978, and 1980. This module provides a complete picture of the household's expenditures and sources of income, defined so that total expenditure equals total receipts. Respondents are asked about income from various economic activities, as well as unearned income such as transfers, inheritance, and sale of assets. With regard to expenditure, these data include information on the quantity and value of 
consumption for 203 detailed food items in the previous week and 103 non-food items in the previous one month and one year. Data are collected on the following energy-related items: electricity, liquefied petroleum gas, natural/city gas, kerosene, diesel, gasoline, lubricants, charcoal and firewood, as well as expenditures related to the use of generators and motor vehicles.

The analysis dataset consists of a single observation per sampled household that contains variables for the expenditure and quantity of each combustible fuel, plus total nominal household expenditure, as well as data from the core questionnaire on household composition and demographic characteristics. Nominal household expenditure is deflated with the consumer price index $(2000=100)$ published in the United Nations Common Database. Less than half of one percent of households are dropped from the estimation sample in each year due to zero expenditure on all combustible fuels, leaving roughly 50,000 household-level observations per year. Total expenditure is used in preference to the conventional notion of income because it is better defined and measured, especially in an economy in which income derives from selfemployment in agriculture and other family enterprises. In addition, total household expenditure is a better measure of "permanent income" in that it is less prone to vary with the idiosyncratic and aggregate shocks that are important sources of income fluctuations in the developing world.

There are two important limitations of the data; we lack data on both fuel prices and accessibility. Prices could be inferred from the information on quantity and expenditure, but only for households that have non-zero consumption. It would be possible to impute prices for those households with zero consumption, based on the implied prices calculated from consumer households, but it is also necessary that we account for significant local variation in energy prices (Pitt, 1985) both within and across years. The survey design makes this infeasible, as the 
number of households surveyed within each locality (kabupaten) is small by design, in order to obtain a nationally-representative sample. With a small sample for imputation, the procedure becomes more unreliable and subject to both measurement and recall error, particularly in the early years when access to modern fuels was more limited.

\subsection{Demographic Change in Indonesia 1980-2002}

Table 1 presents means and standard deviations for a variety of demographic characteristics for each survey year. All aggregate statistics are computed with sampling weights in order to provide figures that are representative of the country of Indonesia as a whole. Household size has decreased in each period, largely driven by a reduction in fertility, as evidenced by the decline in the average number of children under age 17 per household (Figure 1). An aging of the population is also evident in both the average age of household heads and the average number of adults aged 55 and above per household. Male household headship has remained relatively constant, with perhaps a modest decline overall. The population has become increasingly urban over time, with the proportion of households living in urban areas more than doubling between 1980 and 2002. Monthly household expenditure (inflation-adjusted) has also more than doubled over the period, with per capita expenditure growing more rapidly than overall expenditure, given the decline in average household size. Lastly, average and overall educational attainment has increased substantially over the period, as represented by the schooling level of the household head. The fraction having completed junior/senior high or college increased in each survey year, while the fraction with no schooling declined in each year.

\subsection{Trends in Fuel Use}

Figure 2 displays the proportion of households using each energy-related good across the six years of data. Kerosene usage declined modestly in each year of observation, with a more 
marked decline between 1993 and 1999 and slight uptick again in 2002. During this time, liquefied petroleum gas (LPG) usage increased dramatically, from less than $1 \%$ of the population to just over $10 \%$, likely pointing to substitution of LPG for kerosene as cooking fuel. Parallel trends of decreased reliance on biomass and a shift toward modern fuels are evident in the data, particularly throughout the 1990s. Electricity and LPG usage increased steadily throughout this period while usage of charcoal and firewood declined. These trends coincide with a period of rapid growth in household expenditure, which is consistent with the "energy transition" observed in other developing countries. However, as Jiang and O’Neill (2004) note, these trends do not provide a complete picture of energy consumption and the potential implications for the environment. In particular, policymakers might be interested in the quantity of biomass consumed, fuel mix and total energy usage.

Table 2 displays the average quantity purchased for four of the five main sources of household energy usage (electricity, LPG, kerosene, and charcoal) as well as aggregate household energy consumption, in barrel oil equivalents (see Appendix, Table A1 for conversion factors) across these five categories. The overall average provides a sense of changing national energy consumption, while the average quantity among households with non-zero purchases gives a better sense of energy usage within a typical household. Consumption of electricity increased substantially over the period, while we see that increases in LPG consumption are driven entirely by an increase in the number of consumers. There is also some evidence of improvements in efficiency for LPG, as purchases among consumers actually declined slightly over the period. With the exception of the early years for electricity, the quantities purchased by the average consumer exhibit a more stable trend over time, which suggests that consumption decisions for electricity and LPG may be determined more by access and availability than by 
consumer preferences. Kerosene consumption decreased slightly, according to both measures, evidence of decreasing prevalence of charcoal use coupled with falling purchases among consumers. The quantity of charcoal purchased, averaging over all households in the sample, declined steadily after 1990 . This is driven entirely by a reduction in the proportion of households consuming charcoal, as the average quantity purchased, conditional on having nonzero consumption of charcoal, increased over the same period. In fact, of households consuming charcoal, the average quantity purchased more than tripled between 1990 and 2002.

For firewood, quantities cannot be ascertained, as the data include only the total value of firewood consumed ${ }^{1}$ by the household; both quantity and total value are reported for other fuels. Without data on the quantity of firewood consumed, it is difficult to quantify changes in total energy usage by the average Indonesian household, as over half utilize firewood. However, the price of firewood is proportional to the price of charcoal (see Pitt, 1985) and, if this proportionality remains roughly constant over time, data on firewood expenditures and charcoal prices can be used to ascertain a trend in the quantity of firewood consumed. ${ }^{2}$ Table 3 displays the average real value of firewood utilized and the imputed real price of charcoal. Over the period as a whole, we see that the average value consumed increased substantially, both among consumers $(67 \%)$ and in the population as a whole $(46 \%)$, while the imputed charcoal price declined by roughly $51 \%$. However, this price increase was likely outpaced by real wage growth.

\footnotetext{
${ }^{1}$ The bulk of household firewood is gathered personally rather than purchased in markets. Arnold et. al. (2003) note that, even in 1993, about 55\% of household firewood was collected for free. This, along with the fact that quantities of firewood are difficult to estimate accurately, makes it challenging to gather consumption data on firewood. Acknowledging this, survey respondents are not asked to report a quantity for firewood, only the total value. Moreover, enumerators are given explicit instructions to prompt respondents to provide the estimated value of any firewood that is not purchased (Central Bureau of Statistics, 1990).

${ }^{2}$ Unlike charcoal, the implicit cost of firewood entails changing labor costs as well, given the prevalence of fuelwood collection, primarily for rural residents. Using data from Indonesia's Labor Force Survey (SAKERNAS), Dhanani and Islam (2004) show that the rural-urban wage gap fluctuated by less than $25 \%$ over the study period, remaining in a relatively narrow range (57-70). These fluctuations are modest in comparison to the changes in both firewood consumption and the imputed charcoal price.
} 
Dhanani and Islam (2004) find real wage growth of 5 percent per annum in the two decades leading up to the financial crisis and, by 2000 , wages had recovered to around $90 \%$ of their precrisis level. This implies that, even if there were no additional increase after 2000, real wages would have increased by roughly $85 \%$ over our study period (5\% per annum from 1980 to 1997). This exceeds the increase in charcoal prices by more than 30 percentage points, implying a sizable increase in the real price of firewood. A crude calculation using these values indicates that, on average, the quantity of firewood consumed has increased by roughly $12 \%$ over our study period ${ }^{3}$, though there are clearly several caveats, as previously discussed.

Using the same approach, we can examine changes between survey waves as well, though it is more difficult to find comparable data on wage growth. Between 1980 and 1984, the overall increase in value exceeds the reduction in price, even allowing for an additional 5\% increase per annum due to wage growth. However, this is not true for the increase in expenditure among consumers suggesting that, while the number of firewood consumers increased, typical firewood usage declined. Conversely, between 1984 and 1999, price increases outpaced the increase in consumption value, even assuming moderate wage growth of $<4 \%$ per annum, which suggests a decline in the total quantity consumed. Interestingly, after the Asian Financial Crisis, in 1999, there is also a dramatic decline in the average value of firewood consumed, indicative of the severity of the crisis as well as the transition to modern fuels. And in 2002, we observe a rebound, with a large increase in firewood consumption, though it is difficult to determine the increase in quantity without more precise estimates of wage growth during this period.

Returning now to overall energy consumption, which is calculated by aggregating all fuel purchases, measured on the basis of energy output (barrel oil equivalents), we see an increase in

\footnotetext{
${ }^{3}$ The charcoal price decreased by $51 \%$ while real wages increased by $85 \%$, implying a net price increase of $34 \%$ for firewood. In comparison, the real value of consumption increased by only $46 \%$. The difference between the increase in total consumption value and the increase in real price suggests an increase in quantity consumed of only $12 \%$.
} 
the early 1980s, followed by a slightly larger decline in 1987. Average energy consumption is then amazingly stable before increasing again in the late 1990s, likely after the Asian Financial Crisis. The probable changes in the quantity of firewood consumed, as described above, parallel these trends quite closely, with a moderate increase in 1987, followed by a decline through much of the 1990s and a rebound thereafter. This suggests non-trivial improvements in energy efficiency in the first part of the study period, though this seems to have been outpaced by increases in overall energy demand in later years.

To look more closely at energy transition, Table 4 provides the share of each fuel in total household energy expenditure. First, we see that real household energy expenditure has been quite stable throughout our study period, with the exception of a large increase - more than double - between 1980 and 1984. Energy expenditures as a share of total expenditure have fluctuated more widely, though the changes are relatively small, with the exception of 1980-1984 and 1993-1999. Up to 1990, the share of electricity in the fuel budget is increasing steadily, but the shares for LPG, charcoal, and firewood all exhibit decreases between 1980 and 1984 and then increase again in 1987 and 1990. However, from 1990 on, there is clear evidence of an energy transition. The fuel mix for Indonesian households shifted away from biomass - charcoal and firewood - and towards "modern" fuels, particularly electricity and, to a lesser extent, LPG. Kerosene is unique in this context; the high and declining share of kerosene, until 2002, does not obviously fit into a traditional notion of energy transition. This is likely due to the Indonesian government's use of subsidies for modern transport and cooking fuels (gasoline, diesel, kerosene) throughout the study period (Dillon et. al., 2008). We return to this issue in the empirical analysis.

\section{Econometric Methods}


To quantify the relationship between income, demographic characteristics and fuel consumption, we specify a reduced form expenditure equation for each fuel type $\mathrm{e}^{4}$ (electricity, kerosene, charcoal, firewood, liquefied petroleum gas). The expenditure equations for a representative household are of the form

$$
V_{i j t}=\beta_{i t}^{0} \ln \left(Y_{t}\right)+\beta_{i t}^{Y}\left[\ln \left(Y_{t}\right)\right]^{2}+\sum_{k} \beta_{i t}^{k} H_{t}^{k}+\sum_{m} \beta_{i t}^{m} C_{i j t}^{m}+\alpha_{i t}+\omega_{i j}+\varepsilon_{i j t}
$$

where $V_{i j t}$ represents the share of the total household budget spent on fuel type $i$ in community (province) $j$ at time $t$. Total real household expenditure per capita is represented by $Y$. Household characteristics $H^{k}$ include sex, age and schooling of the household head, household size, urban residence, and the fraction of household members in nine age and sex specific categories. Community-level characteristics $C^{m}$ include measures of fuel access and the local value of kerosene subsides, discussed in detail below. The parameters $\alpha_{i t}, \omega_{i j}$ and $\varepsilon_{i j t}$ capture, respectively, the unobserved time-varying characteristics which are constant across all households, characteristics which vary across provinces but are constant over time, and idiosyncratic shocks. With this specification, we allow the spatial distribution of the population (the distribution of $\omega_{i j}$ ) to have an effect on fuel expenditure separate from the effect of other demographic characteristics, including urban/rural residence. To further allow the effect of exogenous household characteristics $H$ on fuel expenditure to vary across income groups and across households of varying size, we specify $\beta_{i t}^{k}$ and $\beta_{i t}^{m}$ as follows:

$$
\beta_{i t}^{k}=\beta_{i t}^{k^{0}}+\beta_{i t}^{k^{Y}} \ln \left(Y_{t}\right)+\beta_{i t}^{k^{S}} \ln \left(S_{t}\right) \text { and } \beta_{i t}^{m}=\beta_{i t}^{m^{0}}+\beta_{i t}^{m^{Y}} \ln \left(Y_{t}\right)+\beta_{i t}^{m^{S}} \ln \left(S_{t}\right)
$$

where $S$ represents $\log$ household size.

Accessibility of fuel is an important determinant of consumption, and vice versa. Ideally, we would utilize direct measures of local supply, market access, and infrastructure. In the

\footnotetext{
${ }^{4}$ Fewer than $0.5 \%$ of households in any sample year report using city/natural gas, resulting in insufficient data to estimate the Tobit likelihood function for this fuel.
} 
absence of such data, we develop a proxy measure defined as the proportion of survey households within the community (province) using electricity. This varies from year to year and can be interpreted as a very rough proxy for changing fuel availability. There were insufficient observations to reliably calculate usage at the kabupaten (district) level; however, usage at the kabupaten level would also be much more closely linked to local demand, making it more difficult to determine the direction of causation. Accessibility is also important for other modern fuels, for which there are less likely to be numerous, if any, local producers. Where the demand for a fuel is limited, retailers are less likely to invest in reliable supply channels and competitive pricing schemes, further depressing demand. Unfortunately, because our proxy is also closely tied to local fuel demand, we include only the proportion of households using electricity, for which local supply is heavily dependent on infrastructure and longer-term investments, rather than short-term fluctuations in consumer demand.

Due to data limitations, our specification does not include fuel prices. Rather, we rely on the year of survey indicators to capture broad changes in prices over time, including changes in fuel subsidies, which are governed by national policy. Of course, there are still likely to be differences across regions in the real impact of these subsidies. An analysis of changing subsidy regimes and local fuel prices over the entire period is beyond the scope of our study, but we can include a rough proxy for kerosene subsidies and its impact on the local market. We define this variable as the local (province) price of kerosene, relative to the U.S. Kerosene-Type Jet Fuel Wholesale/Resale Price by Refiners, obtained from the U.S. Energy Information Administration. This price ratio provides an indication of how much local kerosene prices differ from international prices and, therefore, the extent of the subsidy.

\subsection{Estimation Strategy}


All years of data are stacked together, and the expenditure equations are estimated with Tobit maximum likelihood techniques, allowing for multiplicative heteroskedasticity that varies by year of observation. This would be equivalent to estimating Tobit equations one at a time, except that the province fixed effects $\left(\omega_{i j}\right)$ do not vary over time. Each demand equation has 17 household demographic characteristics and two community characteristics, each interacted with log household size and log household expenditure per capita, plus log household size and its square, log household expenditure per capita and its square, the interaction of log household size and $\log$ household expenditure per capita, and a constant term, giving a total of 63 parameters per year. For each fuel, there are seven years of data and thus seven sets of parameters, requiring the estimation of 441 parameters per fuel. In addition, there are also 26 province dummy variables and 6 variables included in the specification of the conditional variance; the total number of parameters is thus 473 per fuel. The advantage of stacking the data is that it provides maximum likelihood estimates of the entire parameter covariance matrix. The cross-equation parameter covariances are required for tests of parameter constancy over time. Table 5 summarizes the results of pairwise null hypotheses that the parameters of the demand for each fuel in year $t$ are equal to the parameters of the demand for that fuel in year $t^{\prime} \neq t$, where $t=1980$, 1984, 1987, 1990, 1993, 1999, and 2002. For all five major sources of household energy consumption in our analysis - electricity, kerosene, charcoal and firewood, and liquefied petroleum gas - this null hypothesis is rejected at the 0.01 level in every case.

\subsection{Characterizing the Results}

As described above, the flexibility of the empirical specification greatly increases the number of regression coefficients, making it more difficult to interpret individual point estimates. Moreover, there are many interaction effects which must also be included. Therefore, to 
summarize the sources of change in energy demand over time, we integrate our econometric analysis with elements of index decomposition analysis. But, unlike previous studies utilizing IDA, our decomposition is based not on the observed shares/intensities across sectors, but rather on the regression coefficients obtained from our econometric analysis. Our data have both timeseries and cross-sectional components, allowing us to examine three distinct sources of change in energy demand in our decomposition: changes in deterministic factors, namely income and demographic characteristics, and changes in underlying structural parameters, i.e. the responsiveness of demand to factors such as income and demographic characteristics, as well as changing features of the macro-economy. Additionally, we can delve deeper into the decomposition to consider the complex interactions between factors and the contribution of specific factors, such as education and urbanization.

Typically, IDA estimates the impact of a single factor by taking the difference between actual energy usage and a hypothetical value, calculated by holding constant that factor, and that factor alone. But, because our specification includes numerous interactions between factors, calculating values by holding only one factor constant will, in effect, lead to double-counting, as the interactions are not held constant. Conversely, allowing only one factor to vary will lead to under-counting. To see this more clearly, note that the change in a fuel budget share over time, $\Delta V_{i j t}$, abstracting from the fact that some households have zero expenditure on some fuels, can be expressed as the sum of several components:

$\Delta V_{i j t}=$ direct effect of change income + direct effect of change in demographics + direct effect of change in parameters + interaction effect of change in income and change in demographics + interaction effect of change in income and change in parameters + interaction effect of change in demographics and change in parameters + triple interaction of income, demographics and parameters. 
The total effect of any one factor involves the direct effect as well as interaction effects. However, these interaction effects cannot be attributed solely to one factor, as they are determined by the contemporaneous changes in multiple factors. Thus, if we naively include them in the total effects for each factor, the sum of these "total" effects would not be equal to the actual change in energy demand.

Instead, we utilize the "jointly created and equally distributed" principle of the revised Laspeyres index (Sun, 1998), and attribute one-half of each two-way interaction and one-third of the three-way interaction to its component factors. Because we use our regression output to construct the decomposition, we select this approach over the more commonly used log mean Divisia index (LMDI) method (Ang and Liu, 2001). The LMDI method has several preferable features, notable passing the factor- and time-reversal tests and is generally the preferred approach (Ang, 2004). However, our regression framework utilizes an additive rather than multiplicative specification, which translates more clearly to the revised Laspeyres method, both theoretically and intuitively. An alternative would be perhaps to utilize a log specification; however, this is infeasible when using microdata, as a large number of households have zero utilization of certain fuels. Finally, with regression analysis, some statistical noise is inevitable, and this residual error can be distributed in a straightforward manner under the revised Laspeyres method. In contrast, the LMDI method does not provide such guidance because the method itself, which is based on aggregate data, provides a perfect decomposition.

Predicted values take the following general form:

$$
E\left(V^{*}\right)=\Phi\left(V^{*} / \sigma\right) V^{*}+\sigma \varphi\left(V^{*} / \sigma\right)
$$

where $V^{*}=\beta_{i t}^{0} \ln \left(\overline{M_{t}}\right)+\beta_{i t}^{M}\left[\ln \left(\overline{M_{t}}\right)\right]^{2}+\sum_{k} \beta_{i t}^{k} \overline{H_{t}^{k}}+\sum_{m} \beta_{i t}^{m} \overline{C_{l \jmath t}^{m}}+\overline{\alpha_{l t}}+\overline{\omega_{l \jmath}}, E()$ is the expectation operator, $\Phi$ is the standard normal cumulative probability function, $\varphi$ is the standard 
normal density function, and $\sigma$ is the standard deviation of $\varepsilon_{i j t}$. Predicted values are calculated at the year-specific population-weighted sample average and can thus be interpreted as the fuel expenditure, as a share of the total budget, for a representative Indonesian household. The direct effect of each factor is taken as the difference between fuel usage in the base year and the predicted change in fuel usage allowing that factor to vary over time as observed in the data, while holding the remaining factors constant. The interaction effects are calculated as the difference between fuel usage in the base year and the predicted change in fuel usage allowing multiple factors to vary simultaneously, net of the direct effects (and, in the case of the triple interaction, net of the two-way interactions as well). ${ }^{5}$ Additionally, the prediction error (the difference between actual and predicted energy use in the target year, allowing all parameters to vary as observed in the data) is also equally distributed across factors. Thus, this methodology provides a complete decomposition, with no residual.

To examine parameter change in greater detail, we compute the estimated change in fuel consumption for a change in each demographic and community characteristic and for changes in income. This, in effect, isolates the contribution of each factor to the demand for each fuel in each year, and we can use these figures to identify which parameters displayed the greatest change over time. Using the estimated regression parameters, we calculate the percentage change in quantity demanded (the average quantity consumed including households with zero consumption) for a percentage change in the characteristic of interest. In the case of discrete characteristics, i.e. province of residence, urban residence, and sex and education level of the household head, we calculate the percentage change in quantity for a shift from zero to one in the variable of interest.

\footnotetext{
${ }^{5}$ For detailed equations, please see the Technical Appendix. Source code (Stata format) is also available from the authors upon request.
} 


$$
\begin{aligned}
& \xi_{m t}=\left(\partial V_{i j t} / \partial X_{m t}\right) \cdot\left(X_{m t} / V_{i j t}\right) \cdot \varphi\left(\boldsymbol{X}_{t} \boldsymbol{b}_{\boldsymbol{t}}\right) \text { if } X_{m} \text { is continuous, and } \\
& \xi_{m t}=\left(\partial V_{i j t} / \partial X_{m t}\right) \cdot\left(1 / V_{i j t}\right) \cdot \varphi\left(\boldsymbol{X}_{t} \boldsymbol{b}_{t}\right) \quad \text { if } X_{m} \text { is discrete. }
\end{aligned}
$$

Note that, given $\mathrm{V}=(\mathrm{Q} \cdot \mathrm{P}) / \mathrm{M}$ (subscripts suppressed) where $\mathrm{Q}$ is quantity consumed and $\mathrm{P}$ is the price, we can express quantity as $\mathrm{Q}=(\mathrm{V} \cdot \mathrm{M}) / \mathrm{P}$. Then, $(\partial \mathrm{Q} / \partial X)=(\partial \mathrm{V} / \partial X) \cdot(\mathrm{M} / \mathrm{P})$ and $(\partial \mathrm{Q} / \partial X) \cdot(X / \mathrm{Q})=(\partial \mathrm{V} / \partial X) \cdot(X / \mathrm{V})$, and the percentage change in the budget share is equivalent to the percentage change in the total quantity demanded, holding income and price constant. The one exception is where $X=M$; in this case, $(\partial \mathrm{Q} / \partial M)=(\partial \mathrm{V} / \partial M) \cdot(\mathrm{M} / \mathrm{P})+(\mathrm{V} / \mathrm{P})$ and $(\partial \mathrm{Q} / \partial M) \cdot$ $(M / \mathrm{Q})=(\partial \mathrm{V} / \partial M) \cdot(M / \mathrm{V})+1$

\section{Results}

Figures 3 through 7 present the components of the change in the budget shares of each fuel over time. The expenditure share in subsequent years consists of the base year (1980) level plus (or minus) changes attributable to each of three indices: demographic change, income change, and parameter change. Negative effects lie under the y-axis at zero. Appendix Table A2 presents the source data for these figures, including the components used to construct each index, and the Technical Appendix provides further detail about the calculation and decomposition of predicted values. Table 6 displays elasticities, by year and fuel. To reconcile the index decomposition analysis with the estimated elasticities, note that elasticities are calculated holding all other factors fixed in the current year, whereas indices are computed relative to the base year. From these, we summarize the sources of change in fuel demand.

Before describing findings for each fuel in detail, we note one common finding across fuels. In terms of magnitude, the single largest factor explaining changes in fuel usage in our model is the triple interaction between parameters, demographics, and income. This is by construction: that is, if the triple interaction of these three factors did not have significant explanatory power, we would have chosen a more parsimonious specification. And, indeed, 
likelihood ratio tests of models excluding either or both sets of interactions reject those more parsimonious specifications. Thus, while we find index decomposition analysis useful for summarizing our results, we urge caution in interpreting these aggregate indices, as much of the underlying variation is, in fact, driven by the interaction of all three factors and cannot be easily attributed to the individual indices. It seems that IDA may be more appropriate for applications involving aggregate data, while micro-data should be exploited in greater detail to highlight more complex and nuanced patterns. However, a limitation of our approach is that, without more detailed information on market structure and characteristics (e.g., price, access, and other supply factors), we are forced to lump these factors together with demand parameters, resulting in a composite "parameters" index that is not particularly informative for energy policy. Thus, we encourage the combination of aggregate and micro data and continued efforts to integrate econometric and index decomposition analyses to characterize energy usage and transition.

\subsection{Electricity}

Parameter change is the largest cause of the increase in electricity usage among households, accounting for $59-86 \%$ of the change in the budget share since 1980 . Recall that parameter change does not only represent shift in tastes in this model, but also structural features of the economy. First and foremost, not all households had access to the electrical grid, particularly in early years, so the movement in parameters over time also reflects change in supply constraints. Ideally, access to the grid should be used in the estimation as households without such access have deterministically zero demand for electricity. Unfortunately, such specific data on electricity infrastructure and utility providers is not available for Indonesia in the relevant time period. The correct model is a switching regimes model in which electricity is available in one regime and unavailable in the other. As more households had access to the grid, 
their demands switch from one regime to another. In the absence of detailed data on electricity infrastructure and providers, we instead use the proportion of the population within the province using electricity as a rough proxy for fuel availability. In Table 6 , we can see that a $10 \%$ increase in fuel availability increases the budget share of electricity between $3.85 \%$ and $5.05 \%$. Although this is a sizable effect, it is generally much smaller than the elasticity with respect to income or household size, suggesting that availability was only a moderate constraint on electricity consumption.

Growth in income is the second largest predictor of changes in the electricity budget share between 1980 and 1993, accounting for 18 to 32\% of the change. In contrast, demographic change has a modest effect through 1993 but overtakes the income index to account for 9.3 and $10.4 \%$ of the change in the electricity budget share in 1999 and 2002 . Looking at the components of the indices, we see that effect of parameter change, both direct and indirect through interactions with other variables, is almost always positive. That is, changes in the structure of the economy have consistently favored greater expenditures on electricity, as a share of the total budget. Conversely, the positive effects of both demographics and income on electricity consumption operate almost entirely through the triple interaction and the interaction with parameters. Demographic change, in and of itself, would have led to a decrease in the budget share for electricity, in the absence of any structural change in the broader economy. Similarly, income change would have led to only a very slight change in electricity consumption, negative through 1990 and positive thereafter, in the absence of structural change. These are key insights generated by our methodology and indicate that differentiation of the components of broad indices is an important area of continuing research. 
Turning next to the elasticities, we see an overall trend toward less elastic demand for electricity, with almost all estimates decreasing in magnitude over time. This is consistent with energy transition, in the sense that electricity evolves from luxury/normal good to necessity as access improves and use of traditional fuels declines. Indeed, the income elasticity declines in magnitude and actually becomes negative after 1987 . However, this should not be taken as an indication that electricity is an inferior good. Rather, it is likely the combination of two factors. First, given the large changes in the proportion of the population using electricity, demand was likely increasing more rapidly on the extensive margin than on the intensive margin. That is, income growth led to a larger increase in the proportion of the population using electricity than in the amount of electricity used by the average consumer. And in later years, improvements in efficiency likely began to play a larger role as well, with wealthier households better able to purchase energy-saving appliances. This is also consistent with changes in the elasticity with respect to household size; the negative elasticity in later years points to efficiency gains via returns to scale. However, the magnitude of this effect declines in 1999 and 2002, perhaps indicative of the proliferation of personal electronic devices.

Somewhat surprisingly, the estimated elasticities indicate that the impact of urban residence on electricity usage are generally on par with the impact of education, particularly at higher levels. This suggests that continuing urbanization will not have a disproportionately large effect on electricity demand, at least with respect to residential consumption. Moreover, schooling seems to play a role above and beyond income, perhaps by providing education about the adverse health and environmental effects of traditional bio-fuels. Finally, we note that the impact of electricity availability increases through 1990, then declines somewhat before seeming 
to stabilize. The latter decline would seem to reflect both a saturation of potential markets, with respect to infrastructure for electricity, and the increasing importance of reliability versus access.

\subsection{Liquefied Petroleum Gas (LPG)}

In the case of LPG, the three elements of our index decomposition analysis are much more evenly balanced. Income growth explains the largest proportion of changes in the budget share, excepting 1984, but demographic and parameter change both follow closely behind. Consistent with this, when we examine the components of the indices, we see that the triple interaction is the largest through 1993, while the interaction of parameters and income is the largest in 1999 and 2002. Note also that LPG is generally distributed in canisters, so local infrastructure is less likely to be a constraint, although availability and price may still differ widely across regions. These findings indicate that changes in LPG use cannot be readily explained by any one factor; it is the combination of simultaneous changes in income, demographics, and parameters that are driving increased LPG use. However, this pattern is likely to be quite different in later years, as Indonesia implemented a kerosene-to-LPG conversion program in 2007 (Budya and Arofat, 2011).

Looking next at elasticities, we see that they generally increase in magnitude over our study period, opposite the pattern observed for electricity. This suggests that any transition towards LPG and away from traditional fuels was still in the early stages and, thus, demand was still relatively elastic as households gradually adjusted to changing LPG availability and cost. Education plays an even larger role for LPG than for electricity, perhaps indicating limited knowledge of the fuel as an alternative. Urban residence again has a moderate effect, consistent with ready distribution of LPG even in the absence of specific market infrastructure. The much larger elasticities for income and household size suggest that income growth and demographic 
change may have a much larger effect in the future. However, these will likely work in opposite directions, as household size has been decreasing, and the positive elasticity with respect to household size suggests that there are not significant economies of scale in LPG use. Finally, as a word of caution, we note that, given the very small share of LPG in total household expenditure, the point estimates are less precise than for other fuels.

\subsection{Kerosene}

Change in parameters is, by far, the largest source of change in the demand for kerosene and, without concurrent changes in the other indices, the change in parameters alone would have predicted an even greater increase in kerosene expenditure. Conversely, income growth alone would have predicted a substantial decline in the kerosene budget share. Demographics explain less than $10 \%$ of the change. Looking at the components of the indices, we see that the composite indices are actually quite similar, in both sign and magnitude, to the "direct" effects of parameters, income, and demographics. Although the double- and triple-interactions are quite large, they offset each other almost entirely. Indeed, the interactions are generally the largest in magnitude of all the index components, suggesting that broader systemic change - involving parameters, income, and demographics - is the primary driver of changes in kerosene use. In this case, the index decomposition alone may be somewhat misleading, as it forces the assignment of each component, in whole or in part, to a specific index, rather than acknowledging the import of the factors acting in concert.

Demand for kerosene is generally quite inelastic. Only the elasticities with respect to income and household size exceed one in any year. Consistent with the negative income index, the income elasticity is negative as well, with the exception of 2002. This suggests that kerosene is an inferior good; not only do expenditures on kerosene increase more slowly than income, 
households actively seek out opportunities to substitute away from kerosene use as income increases. The elasticity with respect to the kerosene subsidy is also consistent with inelastic demand. With the exception of 1984 and 1987, and increase in the kerosene subsidy - measured as the average kerosene price within the province, divided by the US price - leads to a slight increase in kerosene expenditure, suggesting that households do not readily substitute towards other fuels even as the price of kerosene rises.

The elasticity for household size points to significant economies of scale, with larger families utilizing less kerosene. Additionally, larger households may have greater incentive to switch to modern fuels, given that any fixed costs of adoption/switching can be shared by a larger number of members. Both education and urban residence have a much more muted effect on kerosene, in comparison to electricity and LPG, consistent with kerosene as a familiar traditional fuel that is readily available throughout the country. Finally, consistent with the large effect of parameters discussed above, we see large changes in the elasticities over time as well. As an example, the elasticity of kerosene consumption with respect to monthly household expenditure per capita was -1.012 in 1999 (Table 7), which indicates that the 115 percent increase in real per capita household expenditure between 1980 and 1999 would have led to a 116 percent decline in the average quantity of kerosene consumed, other factors held constant. In contrast, evaluating the same income change with the 1980 income elasticity would predict only a 36 percent decline in kerosene consumption.

\subsection{Charcoal}

Changes in the demand for charcoal are strongly affected by all three indices, to differing degrees over time. Parameters play the largest role, followed by income, while the demographic index generally predicts declining use of charcoal over time. However, looking at the 
components of these indices again reveals that it is the interaction of all three factors driving changes in consumption of charcoal, while the two-way interactions are consistently negative. This is quite an intriguing pattern; the direct effects of parameters, demographics, and income are almost all positive, but when combined with only one other factor, the effect is negative and quite large. As an example, although wealthier families and larger families use more charcoal, those families that are both wealthy and large use much less. But, when we then allow for changing market parameters as well, the model predicts an increase in charcoal usage, consistent with that observed in the data.

Turning to the elasticities, only one clear patterns emerge over time. The effect of urban residence decreases steadily in magnitude, suggesting a widening rural-urban gap, perhaps related to divergences in prices and access. Education appears to have a non-linear effect, with charcoal usage increasing in education up to senior high school or college. But the magnitude of these coefficients exhibits no obvious trend over time. And it is not until 1987 that we begin to see education actually having a negative effect on charcoal usage. This is somewhat surprising, given the strong relationships observed between education and both electricity and LPG. The income elasticity is generally positive and increasing in magnitude over time, with the exception of years closely following recessions $(1984,1987,1999)$. These patterns may, perhaps, suggest that charcoal usage, while not inelastic, is subject to some minimum threshold (e.g., if household have a strong taste preference for food cooked with charcoal). Household size also has a generally increasing positive effect, consistent with the fact that more household members can both increase demand and reduce the implicit cost of using charcoal. Finally, we should note that, given the very low proportion of the household budget allocated to charcoal, the goodness- 
of-fit of our model for charcoal is low, relative to the more prevalent fuels, so our estimates should be interpreted with greater caution as well.

\subsection{Firewood}

Parameter change is, far and away, the largest source of change in the firewood expenditure share, though income growth has played a large role as well. In this case, it is very clear that firewood is an inferior good, with consumption declining as income rises, all else equal. This is evident in the implied income elasticity as well, which is consistently negative and very large in magnitude (-2.04 to -5.16); indeed, in 1984 and 1987, a 20\% increase in income results in a larger decrease in firewood consumption than a switch from rural to urban residence. The elasticities also reveal large negative effects of urban residence and education, both of which are fairly stable over time. Interestingly, the elasticity with respect to household size is consistently negative and relatively large, despite the fact that the majority of firewood is gathered by household members rather than purchased in markets. This suggests that the economies of scale associated with transitioning to modern fuels exceed any reduction in the implicit cost of firewood associated with larger household size.

Returning to the indices, we observe a pattern similar to charcoal in that the triple interaction term is large and positive, while the two-way interactions are negative. However, in this case, we see that the direct effects of income and demographics are negative as well. In fact, the demographic index is positive only because of the triple interaction. This is consistent with the large negative elasticities observed for education and urban residence, given increasing education and urbanization over the study period. Again, our results suggest caution in interpreting these aggregate indices, as they mask important underlying patterns. Demographic change and income growth alone would not, according to our model, have led to any increase in 
firewood usage. Rather, the observed increase can only be explained by the combination of these factors with changes in the structural features of the economy.

\subsection{Energy Transition}

To examine our findings with respect to energy transition, we plot the change in actual budget share for each fuel with the change in total energy expenditure over time (Figures 3-7). For ease of comparison, the two are plotted on different scales, so can informally assess whether growth in fuel-specific expenditure has out-paced growth in total energy expenditure. For the modern fuels - electricity, LPG, kerosene - this is certainly true from 1993-2002. There is a very dramatic increase in the share of the total household budget devoted to each fuel, paired with only modest growth in total household energy expenditure. In the case of electricity and LPG, this pattern is evident, though less dramatic, beginning even in 1980, while the slight dip in the budget share of kerosene in the 1980s is likely driven, at least in part, by increasingly generous government subsidies. Conversely, for charcoal, the budget share has been decreasing since 1993, though the rate of decrease between 1993 and 1999 appears to be comparable to that for total energy expenditure. The budget share for firewood increases steadily throughout our study period, roughly on par with total energy expenditure, with one notable exception. Between 1980 and 1984, total energy expenditure grows dramatically, while the share of firewood in the total budget increases only slightly, and the same is true for charcoal.

These trends together are consistent with energy transition and may reflect differences between the intensive and extensive margins, with the many new users of modern fuels having relatively low per capita consumption, even as aggregate consumption is increasing dramatically. It may also be the case that the energy transition in Indonesia had two stages - in the initial stage, households substantially reduced their usage of biofuels and began to adopt modern fuels while, 
in the second stage, usage of modern fuels increased much more dramatically, as access improved and the number of devices using those fuels increased as well. To examine this, we construct our predicted values and indices using 1990 as the base year (Appendix Figures A6A10). Although the results are less striking in terms of magnitude, they are remarkably similar to our main results. Parameter change remains generally the largest driver of changes in energy use, though the three factors are again more balanced in the case of LPG. For charcoal, however, using 1990 as the base year results in a much smaller effect of income, with parameter change instead driving virtually the entire change in charcoal usage. The energy transition also becomes a bit clearer here, as we see steady increases in electricity, LPG, and kerosene use, accompanied by a steady decline in charcoal use. However, the decline in firewood usage appears to have occurred almost entirely in the earlier portion of our study period, as usage increased on pace or more rapidly than total energy expenditure from 1990 onward.

To validate our interpretation of the energy transition, we repeat our analysis using expenditure on each fuel as a share of the total energy budget, rather than as a share of total household expenditure. This provides a much more direct assessment of energy transition and confirms our main results. However, one caveat is that this approach implicitly assumes twostage budgeting, wherein the household first determines the expenditure share for aggregate categories, one of which is energy, and then determines shares for specific goods within each category. In order for this assumption to be valid, it must be the case that utility in the aggregate categories is weakly separable. This assumption may be overly restrictive, given evidence of links between use of specific fuels and health/productivity (e.g., Duflo et. al., 2008; Pitt et. al. 2010). Thus, we maintain the original specification as our preferred results and present these findings as a robustness check. 
In Figures A1-A5, we see (proportionally) large increases in the share of electricity and LPG in total energy expenditure throughout the study period, and steady but more modest reductions in the share of charcoal and firewood from 1990-2002. The increases in charcoal and firewood usage between 1984 and 1990s seem to be an exception to the general downward trend and may have been driven by the economic downturns in 1982 and 1985. We do not observe a similar response after the 1997 Asian Financial Crisis, but this is perhaps because the energy transition had already progressed much further. The findings for kerosene do not fit as well with the standard energy transition, as the share of kerosene in the energy budget declined throughout much of our study period. However, this may be driven by the increased value of kerosene subsidies throughout this period, rather than reductions in the quantity of kerosene consumed or changes in the underlying demand for kerosene relative to other fuels.

\subsection{Demographic Effects}

Table 7 summarizes the importance of demographic variables in understanding household energy demand in Indonesia. Columns (1) - (4) provide elasticities highlighting the importance of demographic variables in explaining inter-household variation in energy demand in 2002. Looking at the elasticities with respect to household size, we find evidence of economies of scale for electricity and firewood, with larger households using proportionally less, and the opposite is found for LPG, kerosene and charcoal. The effects for firewood, charcoal and LPG are very large, indicative of larger households switching away from firewood entirely and adopting both charcoal and LPG, perhaps sequentially or alternately, depending on local availability. In contrast, the effects for electricity and kerosene are much more modest, suggesting adjustment primarily on the intensive rather than extensive margin. Additionally, improvements in energy efficiency for devices utilizing electricity and kerosene may be offsetting, allowing similar 
consumption of amenities with lower quantities of fuel. Aging of the population seems generally to encourage energy transition as well, with older household heads consuming substantially more electricity and LPG and markedly less charcoal. Firewood usage, however, may be subject to some habit formation, with older household heads actually having moderately higher consumption. If that is the case, then we would expect to see larger changes over time, as later generations acquire greater influence over household energy purchases.

Education increases demand for modern fuels (electricity and LPG) tremendously, with the opposite effect on biofuels (charcoal and firewood), and a negligible effect on kerosene. Because the elasticities are calculated holding all other factors constant, they should be interpreted as the effect of education independent of correlated factors such as income, fertility, and urban residence. This suggests that, during our study period, the transition to modern fuels was strongly driven by knowledge about and/or preferences for health and/or ecological impacts, which would tend to be more prevalent among the highly educated. As in other studies, we find that urbanization has a large impact on demand (column 3), particularly for biofuels that are in more abundant supply in rural areas (charcoal and firewood). This effect is less pronounced for the other fuels, but this is a case where the elasticity has changed substantially over time. In the earlier portion of our study period, when urban residence was much more closely linked with access to modern fuels, urban residence also had a much larger impact on the demand for electricity, LPG, and kerosene (see Table 6). Nonetheless, a clear pattern emerges: households in urban areas have substantially higher demand for modern fuels, particularly electricity and LPG, and much lower demand for traditional bio-fuels, and continued urbanization should significantly accelerate the pace of the energy transition in Indonesia. 
Finally, column (5) displays the composite demographic index, as a percentage of the total change in demand over our study period (1980-2002). Recall that our construction of the index involves equally distributing interaction effects, as well as a residual term, across factors. Using this approach, we estimate that demographic change accounts for 0 to 26 percent of the change in fuel demand. While the magnitude of the demographics index may appear modest in comparison to the other columns, note that the elasticities discussed above characterize differences in energy demand across households within a year. Thus, the elasticities should be interpreted relative to the demand of a representative household. In contrast, the demographics index summarizes the overall contribution of demographic factors on energy demand over time, and should be interpreted relative to the total change in energy demand between 1980 and 2002. To illustrate this, consider the case of electricity. In 2002, the average quantity purchased was $75.52 \mathrm{kwh}$; moving from a rural to an urban area would have increased the consumption for a representative household by $32.53 \%$, or roughly $24.57 \mathrm{kwh}$. Between 1980 and 2002 , the average quantity of electricity purchased increased by $73.72 \mathrm{kwh}$; the demographics index explains $10.42 \%$ of this change, or $7.68 \mathrm{kwh}$. However, this is roughly a $427 \%$ increase in electricity consumption relative to 1980. Thus, for fuels that have exhibited large changes in consumption over the study period (all except kerosene), the demographics index somewhat understates the importance of demographic factors.

Nonetheless, despite the significance of demographic factors in explaining cross-sectional variance in energy demand, as well as their import for changes over time, the longitudinal variation in energy demand is best explained not by any single index in our decomposition, but by the triple interaction of demographic factors, income growth, and parameter change. Thus, despite the co-incidence of the demographic and energy transitions in Indonesia, our findings 
suggest that policies aimed at accelerating demographic transition (e.g., reduced birth rates) or altering other demographic characteristics (e.g., urbanization) will do little to initiate energy transition - except insofar as those policies prompt broader changes in economic activities and market structure. However, once the energy transition has begun, our elasticity measures suggest that these policies may be effective in accelerating energy transition among marginal households, who already have access to modern fuels and the means to purchase them, as well as underlying demand for cleaner energy sources.

\section{Conclusion}

The findings of this study reveal the importance of using time-series data to assess the progress of the energy transition. We utilize seven repeated cross-section surveys from Indonesia, spanning over two decades (1980-2002) of strong economic growth and substantial demographic change. The data provide clear evidence of an energy transition, with households shifting their energy expenditures away from traditional fuels (charcoal, firewood) and towards modern fuels (electricity and LPG). This appears not only in the share of the budget devoted to each fuel, but also in the quantity consumed. Kerosene appears to occupy an intermediate position; demand declined only slightly over our survey period, consistent with an energy ladder whereby households utilize kerosene as a stepping stone between traditional and modern fuels. However, the latter pattern may be unique to Indonesia, as a result of its continual and heavy subsidization of kerosene throughout our study period.

Our econometric estimates indicate a relatively modest role for demographic factors in initiating or accelerating the energy transition. Demographic change over our survey period reduced demand for traditional fuels and increased demand for modern fuels. All in all, demographic change explains $0-26 \%$ of the observed change in energy demand in Indonesia 
between 1980 and 2002. However, the single largest driver of changes in energy consumption, in terms of both levels and fuel choice, is not any one of our composite indices but the triple interaction of demographics, income growth, and parameter change. This is, in part, by construction. We employ a complex empirical specification that allows specifically for interactions among these factors, and thus the significance of the triple interaction supports this choice over an alternate, more parsimonious specification. We also conduct likelihood ratio tests comparing our model to specifications excluding these interactions, and reject these alternate specifications at the $1 \%$ level in all cases, for all five fuels.

This finding suggests that, although index decomposition analysis can be an extremely useful for isolating the impact of various factors, it can mask significant heterogeneity when utilized to analyze the determinants of household-level energy demand. Variation across households, both in cross-sections and longitudinally, is, in effect, too nuanced to be adequately represented by IDA, or at least IDA approaches utilizing only a small number of indices. Rather, our results suggest that energy transition is precipitated and facilitated primarily by underlying structural change in the economy as a whole, and it must be change that is broad enough to effect demographic factors, income, and demand/supply parameters. This does not rule out the possibility that demographic transition can begin this process but, rather, suggests that demographic transition alone cannot complete this process. And, while economic growth and demographic change do influence energy consumption as expected, changes in the relationship between income, demographics and demand/supply over time explain a much greater portion of the energy transition than do the static relationships between income/demographics and demand. In effect, our findings indicate that, while broad-based economic development provides the impetus for the energy transition, the relationships between factors become magnified over time, 
creating a self-reinforcing cycle. Finally, we note that Indonesia has a long history of subsidizing energy goods, particularly modern fuels (IISD, 2011), and these price controls likely accelerated the energy transition. As a result, our estimates may not be very useful for forecasting, particularly given recent changes in Indonesia's energy policy, and cannot necessarily be generalized to other contexts. Future research should seek to incorporate richer data on prices and access to fuels to disentangle these factors from underlying demand preferences. 


\section{References.}

Ang, B.W., 2004. "Decomposition Analysis for Policymaking in Energy: Which Is the Preferred Method?" Energy Policy. 32(9), 1131-1139.

Ang, B.W., Liu, F.L., 2001. "A New Energy Decomposition Method: Perfect in Decomposition and Consistent in Aggregation." Energy. 26(6), 537-548.

Ang, B.W., Zhang, F.Q., 2000. "A Survey of Index Decomposition Analysis in Energy and Environmental Studies.” Energy. 25(12), 1149-1176.

Ang, B.W., Zhang, F.Q. and Choi, K.H., 1998. "Factorizing Changes in Energy and Environmental Indicators through Decomposition.” Energy. 23(6), 489-495.

Arnold, J.E.M., Kohlin, G., Persson, R. and Shepherd, G., 2003. "Fuelwood Revisited: What Has Changed in the Last Decade?" CIFOR Occasional Paper no. 39. Center for International Forestry Research. Bogor, Indonesia.

Barnes, D. and W. Floor. 1999. "Biomass Energy and the Poor in the Developing Countries." Journal of International Affairs. 53(1), 237-259.

Barnes, D. and U. Qian. 1992. "Urban Interfuel Substitution, Energy Use and Equity in Developing Countries.” World Bank Industry and Energy Department Working Paper, Energy Series Paper 53. Washington, DC.

Barnes, D., K. Krutilla, and W. F. Hyde. 2005. The Urban Household Energy Transition: Social and Environmental Impacts in the Developing World. Washington, DC: RFF Press, Resources for the Future.

Budya, Hanung, and Muhammad Yasir Arofat. 2011. "Providing Cleaner Energy Access in Indonesia Through the Megaproject of Kerosene Conversion to LPG." Energy Policy. 39(12), 7575-7586.

Campbell, B.M., S.J. Vermeulen, J.J. Mangono and R. Mabugu. 2003. "The Energy Transition in Action: Urban Domestic Fuel Choices in a Changing Zimbabwe.” Energy Policy. 31(6), 553562.

Central Bureau of Statistics. 1990. "National Socio-Economic Survey Enumeration Manual." Jakarta, Indonesia. Accessed June 1, 2016. http://www.rand.org/content/dam/rand/www/ external/labor/bps/manualpdf/susenas/susenas 90manualii.pdf.

Central Intelligence Agency. "World Fact Book." Accessed June 6, 2016. https://www.cia.gov/library/publications/the-world-factbook/geos/id.html

Dhanani, S. and Islam, I., 2004. Indonesian Wage Structure and Trends, 1976-2000. International Labour Office, Geneva.

Dillon, H.S., T. Laan, and H. Setyaka Dillon (2008). Biofuels: At What Cost? - Government Support for Ethanol and Biodiesel in Indonesia. Global Subsidies Initiative of the International Institute for Sustainable Development, Geneva.

Duflo, E., M. Greenstone, and R. Hanna. 2008. "Indoor Air Pollution, Health and Economic Well-Being." SAPI EN. S. Surveys and Perspectives Integrating Environment and Society, (1.1).

Elias, Stephen and Clare Noone. 2011. "The Growth and Development of the Indonesian Economy." Bulletin of the Reserve Bank of Australia. December Quarter, 33-44.

Gales, B., A. Kander, P. Malanima and M. Rubio. 2007. "North versus South: Energy Transition and Energy Intensity in Europe Over 200 Years." European Review of Economic History. 11(2), 219-253. 
Heltburg, R. 2004. "Fuel Switching: Evidence from Eight Developing Countries." Energy Economics. 26(5), 869-887.

Holtedahl, P. and Joutz, F.L., 2004. "Residential Electricity Demand in Taiwan." Energy Economics. 26(2), 201-224.

Hosier, R. and W. Kipondya. 1993. "Urban Household Energy Use in Tanzania: Prices, Substitutes and Poverty." Energy Policy. 21(5), 453-473.

International Institute for Sustainable Development. “A Citizen's Guide to Energy Subsidies in Indonesia." Accessed August 1, 2012. http://www.iisd.org/gsi/sites/default/files/indonesia czguide eng.pdf

Jiang, L. and B.C. O'Neill. 2004. "The Energy Transition in Rural China." International Journal of Global Energy Issues. 21(1/2), 2-26.

Leach, G. 1992. "The Energy Transition.” Energy Policy. 20(2), 116-123.

Nie, Hongguang and Rene Kemp. 2014. "Index Decomposition Analysis of Residential Energy Consumption in China: 2002-2010." Applied Energy. 121, 10-19.

Pachauri, S. and L. Jiang. 2008. "The Household Energy Transition in India and China." Energy Policy. 36(11), 4022-4035.

Permana, A.S., R. Perera and S. Kumar. 2008. "Understanding Energy Consumption Pattern of Households in Different Urban Development Forms: A Comparative Study in Bandung City, Indonesia." Energy Policy. 36(11), 4287-4297.

Pitt, M.M. 1985. "Equity, Externalities and Energy Subsidies: The Case of Kerosine in Indonesia." Journal of Development Economics. 17(3), 201-217.

Pitt, M.M., M.R. Rosenzweig, and M.N. Hassan. 2010. "Short- and Long-Term Health Effects of Burning Biomass in the Home in Low-Income Countries." Unpublished Manuscript, Brown University.

Song, F. and Zheng, X., 2012. "What Drives the Change in China's Energy Intensity: Combining Decomposition Analysis and Econometric Analysis at the Provincial Level." Energy Policy. 51, pp.445-453.

Sun, J.W., 1998. "Changes in Energy Consumption and Energy Intensity: A Complete Decomposition Model." Energy Economics. 20 (1), 85-100.

Tobin, J. 1958. "Estimation of Relationships for Limited Dependent Variables." Econometrica. 26(1), 24-36.

World Bank. "World Development Indicators." World dataBank. Accessed July 24, 2012. http://databank.worldbank.org/ddp/home.do? $\mathrm{CNO}=2 \& \mathrm{Step}=12 \& \mathrm{id}=4$

Zhang, Fan. 2013. "The Energy Transition of the Transition Economies: An Empirical Analysis." Energy Economics. 40, 679-686. 
Table 1. Household Demographic Characteristics

\begin{tabular}{lrrrrrrr}
\hline \hline & 1980 & 1984 & 1987 & 1990 & 1993 & 1999 & 2002 \\
\cline { 2 - 8 } Urban Residence & $20.86 \%$ & $22.06 \%$ & $25.79 \%$ & $28.79 \%$ & $30.97 \%$ & $38.53 \%$ & $44.64 \%$ \\
& $(0.406)$ & $(0.415)$ & $(0.437)$ & $(0.453)$ & $(0.462)$ & $(0.487)$ & $(0.497)$ \\
Age of Household Head & 42.88 & 43.24 & 43.83 & 44.38 & 44.93 & 45.58 & 45.18 \\
& $(12.897)$ & $(13.614)$ & $(13.873)$ & $(13.714)$ & $(13.879)$ & $(14.093)$ & $(13.886)$ \\
Male Household Head & $87.18 \%$ & $86.50 \%$ & $86.80 \%$ & $87.62 \%$ & $87.37 \%$ & $86.81 \%$ & $87.77 \%$ \\
& $(0.334)$ & $(0.342)$ & $(0.339)$ & $(0.329)$ & $(0.332)$ & $(0.338)$ & $(0.328)$ \\
\# of Hh Members & 4.809 & 4.677 & 4.607 & 4.565 & 4.379 & 4.114 & 3.972 \\
& $(2.268)$ & $(2.174)$ & $(2.132)$ & $(2.017)$ & $(1.924)$ & $(1.811)$ & $(1.684)$ \\
Monthly Hh Expenditure & 308,336 & 396,823 & 449,408 & 477,671 & 513,878 & 583,339 & 666,438 \\
& $(297168)$ & $(362158)$ & $(416488)$ & $(454522)$ & $(512678)$ & $(506612)$ & $(794612)$ \\
Monthly Hh Exp. Per Capita & 68,610 & 90,942 & 103,790 & 109,902 & 123,105 & 152,728 & 178,822 \\
& $(59466)$ & $(77382)$ & $(88276)$ & $(86147)$ & $(107123)$ & $(122365)$ & $(184564)$ \\
Consumer Price Index & 13 & 19 & 23 & 29 & 37 & 96 & 125 \\
\hline Schooling of Head & & & & & & & \\
\hline No Schooling & $33.12 \%$ & $26.10 \%$ & $22.26 \%$ & $20.28 \%$ & $17.23 \%$ & $13.03 \%$ & $10.95 \%$ \\
& $(0.471)$ & $(0.439)$ & $(0.416)$ & $(0.402)$ & $(0.378)$ & $(0.337)$ & $(0.312)$ \\
Some Primary & $30.68 \%$ & $33.66 \%$ & $32.17 \%$ & $25.73 \%$ & $30.59 \%$ & $23.53 \%$ & $20.93 \%$ \\
& $(0.461)$ & $(0.473)$ & $(0.467)$ & $(0.437)$ & $(0.461)$ & $(0.424)$ & $(0.407)$ \\
Completed Primary & $23.41 \%$ & $25.55 \%$ & $26.48 \%$ & $33.06 \%$ & $28.92 \%$ & $31.07 \%$ & $32.12 \%$ \\
& $(0.423)$ & $(0.436)$ & $(0.441)$ & $(0.470)$ & $(0.453)$ & $(0.463)$ & $(0.467)$ \\
Completed Junior High & $6.66 \%$ & $6.64 \%$ & $8.34 \%$ & $9.02 \%$ & $9.21 \%$ & $11.79 \%$ & $12.83 \%$ \\
Completed Senior High & $(0.249)$ & $(0.249)$ & $(0.277)$ & $(0.286)$ & $(0.289)$ & $(0.323)$ & $(0.334)$ \\
Some College & $5.08 \%$ & $6.98 \%$ & $8.92 \%$ & $9.57 \%$ & $11.34 \%$ & $16.09 \%$ & $17.43 \%$ \\
Number of Observations & $(0.220)$ & $(0.255)$ & $(0.285)$ & $(0.294)$ & $(0.317)$ & $(0.367)$ & $(0.379)$ \\
\hline Source: In & $1.05 \%$ & $1.08 \%$ & $1.82 \%$ & $2.35 \%$ & $2.71 \%$ & $4.49 \%$ & $5.73 \%$ \\
& $(0.102)$ & $(0.103)$ & $(0.134)$ & $(0.151)$ & $(0.162)$ & $(0.207)$ & $(0.232)$ \\
& 56,773 & 50,161 & 51,209 & 46,057 & 58,864 & 61,114 & 64,344 \\
\hline
\end{tabular}

Source: Indonesian National Socioeconomic Survey (SUSENAS).

Standard errors in parentheses.

${ }^{\mathrm{a}}$ Deflated with consumer price index $(2000=100)$ from the United Nations Common Database. 
Table 2. Average Quantity of Fuel Purchased Per Month, Household-Level

\begin{tabular}{lrrrrrrr}
\hline \hline \multirow{2}{*}{ Overall } & 1980 & 1984 & 1987 & 1990 & 1993 & 1999 & 2002 \\
\cline { 2 - 8 } Electricity (kwh) & 1.798 & 16.72 & 19.63 & 22.73 & 32.18 & 60.55 & 75.52 \\
& $(19.292)$ & $(61.084)$ & $(54.750)$ & $(62.418)$ & $(74.586)$ & $(150.890)$ & $(153.400)$ \\
LPG (kg) & 0.099 & 0.062 & 0.229 & 0.360 & 0.441 & 1.131 & 1.665 \\
& $(4.608)$ & $(1.398)$ & $(2.359)$ & $(5.810)$ & $(4.120)$ & $(4.945)$ & $(7.850)$ \\
Kerosene (liter) & 18.176 & 17.695 & 15.173 & 14.597 & 13.593 & 14.354 & 15.127 \\
& $(16.982)$ & $(16.686)$ & $(16.647)$ & $(17.575)$ & $(16.820)$ & $(15.962)$ & $(14.798)$ \\
Charcoal (kg) & 0.371 & 0.317 & 0.416 & 0.363 & 0.297 & 0.108 & 0.028 \\
& $(2.365)$ & $(1.508)$ & $(2.760)$ & $(1.425)$ & $(1.830)$ & $(1.949)$ & $(1.030)$ \\
Total (barrel oil equivalents) & 0.112 & 0.117 & 0.106 & 0.106 & 0.106 & 0.133 & 0.151 \\
& $(0.112)$ & $(0.117)$ & $(0.116)$ & $(0.131)$ & $(0.124)$ & $(0.148)$ & $(0.156)$ \\
\hline \multicolumn{1}{c}{ Consumers Only } & & & & & & \\
\hline Electricity (kwh) & 18.41 & 83.17 & 57.20 & 54.99 & 60.58 & 73.99 & 87.18 \\
& $(59.22)$ & $(114.18)$ & $(81.16)$ & $(87.48)$ & $(93.56)$ & $(163.8)$ & $(161.7)$ \\
LPG (kg) & 20.58 & 18.48 & 17.79 & 18.99 & 16.85 & 15.88 & 16.26 \\
& $(63.16)$ & $(15.45)$ & $(10.93)$ & $(37.79)$ & $(19.31)$ & $(10.44)$ & $(19.09)$ \\
Kerosene (liter) & 18.38 & 17.99 & 15.91 & 15.63 & 15.05 & 16.70 & 17.18 \\
& $(16.97)$ & $(16.67)$ & $(16.70)$ & $(17.74)$ & $(17.07)$ & $(16.04)$ & $(14.61)$ \\
Charcoal (kg) & 2.915 & 2.331 & 2.601 & 2.362 & 2.808 & 4.900 & 7.624 \\
& $(6.048)$ & $(3.470)$ & $(6.476)$ & $(2.913)$ & $(4.966)$ & $(12.17)$ & $(15.29)$ \\
\hline Proportion of Households with Non-Zero Consumption & & & & & \\
\hline Electricity & 0.0976 & 0.2010 & 0.3432 & 0.4133 & 0.5310 & 0.8183 & 0.8663 \\
LPG & 0.0048 & 0.0034 & 0.0129 & 0.0189 & 0.0261 & 0.0712 & 0.1025 \\
Kerosene & 0.9889 & 0.9838 & 0.9535 & 0.9336 & 0.9031 & 0.8593 & 0.8802 \\
Charcoal & 0.1271 & 0.1359 & 0.1600 & 0.1537 & 0.1056 & 0.0221 & 0.0036 \\
Firewood & 0.5771 & 0.6768 & 0.7062 & 0.7143 & 0.6800 & 0.5093 & 0.5053 \\
\hline Source: Indons & & & & & &
\end{tabular}

Source: Indonesian National Socioeconomic Survey (SUSENAS).

Standard errors in parentheses.

Table 3. Average Monthly Expenditure ${ }^{a}$ on Firewood, Household-Level

\begin{tabular}{lrrrrrrr}
\hline \hline & 1980 & 1984 & 1987 & 1990 & 1993 & 1999 & 2002 \\
\cline { 2 - 7 } Overall & 4648 & 8862 & 9282 & 9280 & 9595 & 6078 & 6792 \\
& $(8060)$ & $(10113)$ & $(10143)$ & $(10121)$ & $(10595)$ & $(9059)$ & $(10173)$ \\
Rate of Change & & $90.65 \%$ & $4.74 \%$ & $-0.02 \%$ & $3.40 \%$ & $-36.65 \%$ & $11.75 \%$ \\
Consumers Only & 8055 & 13095 & 13145 & 12991 & 14111 & 11935 & 13443 \\
& $(9227)$ & $(9782)$ & $(9743)$ & $(9756)$ & $(10068)$ & $(9553)$ & $(10743)$ \\
Rate of Change & & $62.57 \%$ & $0.38 \%$ & $-1.17 \%$ & $8.62 \%$ & $-15.42 \%$ & $12.64 \%$ \\
Imputed Charcoal Price (kg) & 2122 & 746.1 & 959.9 & 888.1 & 824.4 & 993.6 & 1032 \\
& $(10544)$ & $(336.2)$ & $(3393)$ & $(2721)$ & $(632.5)$ & $(709.8)$ & $(1097)$ \\
Rate of Change & & $-64.84 \%$ & $28.67 \%$ & $-7.49 \%$ & $-7.17 \%$ & $20.52 \%$ & $3.82 \%$ \\
\hline
\end{tabular}

Source: Indonesian National Socioeconomic Survey (SUSENAS).

Standard errors in parentheses.

${ }^{a}$ Deflated with consumer price index $(2000=100)$ from the United Nations Common Database. 
Table 4. Average Monthly Energy Expenditure, Household-Level

\begin{tabular}{lrrrrrrr}
\hline & 1980 & 1984 & 1987 & 1990 & 1993 & 1999 & 2002 \\
\cline { 2 - 8 } Total Energy Expenditure & 13,239 & 32,485 & 32,669 & 31,104 & 35,650 & 30,721 & 36,048 \\
& $(15563)$ & $(28333)$ & $(33547)$ & $(33303)$ & $(37813)$ & $(44952)$ & $(29351)$ \\
As Share of Total Expenditure & 0.055 & 0.100 & 0.087 & 0.077 & 0.083 & 0.055 & 0.064 \\
& $(0.048)$ & $(0.060)$ & $(0.049)$ & $(0.044)$ & $(0.047)$ & $(0.032)$ & $(0.034)$ \\
\hline As Share of Fuel Budget & & & & & & & \\
\hline Electricity (kwh) & 0.053 & 0.072 & 0.128 & 0.159 & 0.184 & 0.306 & 0.349 \\
& $(0.174)$ & $(0.164)$ & $(0.201)$ & $(0.217)$ & $(0.209)$ & $(0.220)$ & $(0.226)$ \\
LPG (kg) & 0.002 & 0.001 & 0.003 & 0.005 & 0.007 & 0.023 & 0.037 \\
& $(0.040)$ & $(0.014)$ & $(0.031)$ & $(0.040)$ & $(0.051)$ & $(0.094)$ & $(0.120)$ \\
Kerosene (liter) & 0.555 & 0.551 & 0.443 & 0.389 & 0.383 & 0.301 & 0.367 \\
& $(0.334)$ & $(0.278)$ & $(0.266)$ & $(0.264)$ & $(0.277)$ & $(0.261)$ & $(0.264)$ \\
Charcoal (kg) & 0.014 & 0.006 & 0.009 & 0.009 & 0.006 & 0.003 & 0.001 \\
& $(0.059)$ & $(0.028)$ & $(0.037)$ & $(0.033)$ & $(0.031)$ & $(0.030)$ & $(0.015)$ \\
Firewood & 0.342 & 0.338 & 0.372 & 0.388 & 0.365 & 0.284 & 0.245 \\
& $(0.337)$ & $(0.290)$ & $(0.297)$ & $(0.305)$ & $(0.307)$ & $(0.325)$ & $(0.290)$ \\
Number of Observations & 56,773 & 50,161 & 51,209 & 46,057 & 58,864 & 61,114 & 64,344 \\
\hline
\end{tabular}

Source: Indonesian National Socioeconomic Survey (SUSENAS).

Standard errors in parentheses.

${ }^{a}$ Deflated with consumer price index $(2000=100)$ from the United Nations Common Database.

Table 5. Tests of Parameter Constancy

\begin{tabular}{lccccc}
\hline & Eletricity & LPG & Kerosene & Charcoal & Firewood \\
Number of Tests & 21 & 21 & 21 & 21 & 21 \\
Rejected at 1\% Level & 21 & 21 & 21 & 21 & 21 \\
Rejected at 5\% Level & 21 & 21 & 21 & 21 & 21 \\
\hline
\end{tabular}


Table 6. Percentage Change in Quantity Demanded for a Change in Household Characteristics

\begin{tabular}{|c|c|c|c|c|c|c|c|c|c|c|c|c|c|c|}
\hline & \multicolumn{7}{|c|}{ Electricity } & \multicolumn{7}{|c|}{ LPG } \\
\hline & 1980 & 1984 & 1987 & 1990 & 1993 & 1999 & 2002 & 1980 & 1984 & 1987 & 1990 & 1993 & 1999 & 2002 \\
\hline Male Household Head & -0.388 & -0.240 & -0.136 & -0.230 & -0.130 & -0.055 & -0.026 & -0.526 & -1.026 & -0.007 & -0.516 & -1.706 & -0.291 & -0.215 \\
\hline Age of Household Head & 1.153 & 0.702 & 0.513 & 0.338 & 0.310 & 0.337 & 0.367 & -0.500 & 5.181 & 2.711 & 2.528 & 2.486 & 1.024 & 1.612 \\
\hline Completed Primary & 0.996 & 0.721 & 0.496 & 0.467 & 0.318 & 0.225 & 0.254 & 0.420 & 3.220 & 1.967 & 4.363 & 3.490 & 0.990 & 0.847 \\
\hline Completed Junior High & 1.722 & 1.086 & 0.748 & 0.676 & 0.444 & 0.354 & 0.352 & 0.031 & 4.839 & 2.461 & 3.753 & 5.170 & 1.480 & 1.384 \\
\hline Completed Senior High & 2.164 & 1.381 & 0.942 & 0.897 & 0.580 & 0.429 & 0.454 & 0.078 & 6.508 & 3.814 & 4.710 & 5.389 & 2.430 & 2.307 \\
\hline Some College & 2.355 & 1.370 & 0.948 & 0.939 & 0.601 & 0.444 & 0.514 & 0.877 & 5.433 & 5.878 & 6.492 & 7.334 & 3.290 & 3.296 \\
\hline Urban Residence & 2.456 & 1.508 & 0.976 & 0.998 & 0.743 & 0.381 & 0.325 & -0.233 & -1.506 & 0.853 & 2.192 & 2.307 & 0.874 & 0.556 \\
\hline Electricity Availability & 0.385 & 0.414 & 0.551 & 0.584 & 0.531 & 0.485 & 0.508 & 0.515 & 1.037 & 0.150 & 0.540 & -0.426 & -0.372 & 0.753 \\
\hline Kerosene Subsidy & 0.643 & -0.120 & -0.976 & -1.376 & -1.457 & -0.585 & -0.287 & 2.784 & -31.767 & -19.684 & 1.452 & -4.319 & 0.250 & 2.947 \\
\hline Monthly Hh Exp. Per Capita & 2.459 & 1.156 & -0.855 & -1.441 & -2.783 & -1.303 & -0.291 & 3.930 & 9.356 & 0.946 & 11.966 & -3.469 & 3.741 & 5.857 \\
\hline \multirow[t]{3}{*}{ \# Household Members } & 1.173 & 0.175 & -1.494 & -1.187 & -2.663 & -0.509 & -0.295 & 1.368 & -21.537 & -13.313 & 3.401 & 1.954 & -0.041 & 2.327 \\
\hline & \multicolumn{7}{|c|}{ Kerosene } & \multicolumn{7}{|c|}{ Charcoal } \\
\hline & 1980 & 1984 & 1987 & 1990 & 1993 & 1999 & 2002 & 1980 & 1984 & 1987 & 1990 & 1993 & 1999 & 2002 \\
\hline Age of Household Head & -0.011 & 0.042 & 0.032 & -0.028 & -0.039 & -0.010 & -0.028 & -0.298 & -0.326 & 0.010 & -0.130 & 0.029 & -0.136 & -0.490 \\
\hline Some Primary School & 0.013 & 0.014 & 0.028 & -0.044 & -0.026 & 0.019 & 0.028 & 0.288 & 0.048 & 0.001 & 0.143 & 0.240 & 0.459 & -0.134 \\
\hline Completed Primary & 0.041 & 0.021 & 0.016 & -0.012 & -0.013 & 0.060 & 0.051 & 0.479 & 0.300 & 0.028 & 0.310 & 0.236 & 0.456 & -0.246 \\
\hline Completed Junior High & 0.073 & 0.033 & 0.038 & 0.040 & 0.005 & 0.082 & 0.042 & 0.840 & 0.531 & 0.101 & 0.378 & 0.248 & 0.502 & -1.202 \\
\hline Completed Senior High & 0.054 & 0.010 & 0.039 & 0.035 & -0.004 & 0.032 & -0.023 & 1.018 & 0.462 & 0.121 & 0.329 & 0.021 & -0.152 & -0.829 \\
\hline Some College & 0.026 & 0.016 & 0.021 & 0.078 & -0.006 & 0.008 & -0.129 & 0.820 & 0.596 & -0.457 & -0.116 & -0.315 & -1.138 & -2.109 \\
\hline Urban Residence & 0.301 & 0.372 & 0.328 & 0.305 & 0.341 & 0.304 & 0.210 & 1.033 & 0.374 & 0.244 & -0.175 & -0.305 & -0.434 & -1.387 \\
\hline Electricity Availability & -0.026 & 0.033 & -0.005 & -0.107 & -0.041 & -0.189 & -0.050 & 0.387 & 0.261 & 0.103 & -0.370 & -0.504 & -3.089 & 2.274 \\
\hline Kerosene Subsidy & 0.912 & -0.733 & -0.154 & 0.055 & 0.179 & 0.040 & 0.648 & 1.429 & -0.691 & 0.422 & -1.396 & -2.812 & -5.318 & 4.276 \\
\hline Monthly Hh Exp. Per Capita & -0.315 & -1.377 & -0.521 & -0.633 & -0.783 & -1.012 & 0.539 & 1.306 & -2.466 & -0.717 & 1.788 & 9.260 & -10.084 & 6.779 \\
\hline \# Household Members & -0.345 & -1.207 & -0.973 & -1.039 & -0.840 & -0.453 & 0.168 & 1.359 & 0.222 & 0.162 & 0.745 & 5.265 & -6.655 & 5.867 \\
\hline
\end{tabular}


Table 6. Percentage Change in Quantity Demanded for a Change in Household Characteristics (cont.)

\begin{tabular}{lccccccc}
\hline & & & \multicolumn{7}{c}{ Firewood } \\
& 1980 & 1984 & 1987 & 1990 & 1993 & 1999 & 2002 \\
\cline { 2 - 7 } Male Household Head & 0.084 & 0.103 & 0.161 & 0.098 & 0.147 & 0.253 & 0.265 \\
Age of Household Head & 0.041 & 0.029 & 0.095 & 0.108 & 0.162 & 0.290 & 0.132 \\
Some Primary School & -0.044 & -0.069 & -0.058 & 0.007 & -0.048 & -0.100 & -0.243 \\
Completed Primary & -0.147 & -0.200 & -0.206 & -0.071 & -0.167 & -0.289 & -0.471 \\
Completed Junior High & -0.469 & -0.392 & -0.358 & -0.282 & -0.360 & -0.565 & -0.799 \\
Completed Senior High & -0.648 & -0.490 & -0.476 & -0.405 & -0.469 & -0.793 & -1.055 \\
Some College & -1.023 & -0.463 & -0.489 & -0.496 & -0.502 & -0.997 & -1.186 \\
Urban Residence & -0.924 & -0.924 & -0.832 & -0.823 & -0.946 & -1.542 & -1.506 \\
Electricity Availability & 0.350 & 0.154 & 0.129 & 0.248 & 0.137 & -0.721 & -1.093 \\
Kerosene Subsidy & -0.324 & -0.516 & -0.140 & 0.075 & 0.421 & 0.252 & -1.184 \\
Monthly Hh Exp. Per Capita & -2.036 & -5.164 & -4.345 & -3.041 & -2.210 & -2.115 & -3.656 \\
\# Household Members & -1.311 & -2.416 & -2.453 & -1.937 & -0.056 & -0.351 & -1.757 \\
\hline
\end{tabular}

Table 7. Change in Quantity Demanded Due to Various Demographic Factors ${ }^{a}$

\begin{tabular}{|c|c|c|c|c|c|}
\hline \multirow[b]{2}{*}{ Fuel } & \multicolumn{3}{|c|}{$10 \%$ Increase } & \multirow[b]{2}{*}{$\begin{array}{l}\text { Move from } \\
\text { Rural to } \\
\text { Urban Area }\end{array}$} & \multirow[b]{2}{*}{$\begin{array}{c}\text { Demographics } \\
\text { Index } \\
(1980-2002)\end{array}$} \\
\hline & $\begin{array}{c}10 \% \text { Increase } \\
\text { in Household } \\
\text { Size }\end{array}$ & $\begin{array}{c}\text { in Age of } \\
\text { Household } \\
\text { Head }\end{array}$ & $\begin{array}{l}\text { High School } \\
\text { vs. No School }\end{array}$ & & \\
\hline Electricity & $-29.52 \%$ & $36.74 \%$ & $45.36 \%$ & $32.53 \%$ & $10.42 \%$ \\
\hline LPG & $233 \%$ & $161 \%$ & $231 \%$ & $55.56 \%$ & $25.25 \%$ \\
\hline Kerosene & $16.79 \%$ & $-2.84 \%$ & $-2.33 \%$ & $21.03 \%$ & $8.10 \%$ \\
\hline Charcoal & $587 \%$ & $-49.01 \%$ & $-82.85 \%$ & $-138.75 \%$ & $25.91 \%$ \\
\hline Firewood & $-176 \%$ & $13.23 \%$ & $-105 \%$ & $-150.61 \%$ & $-0.42 \%$ \\
\hline
\end{tabular}

${ }^{\mathrm{a}}$ Calculated at 2002 values, unless otherwise noted. 

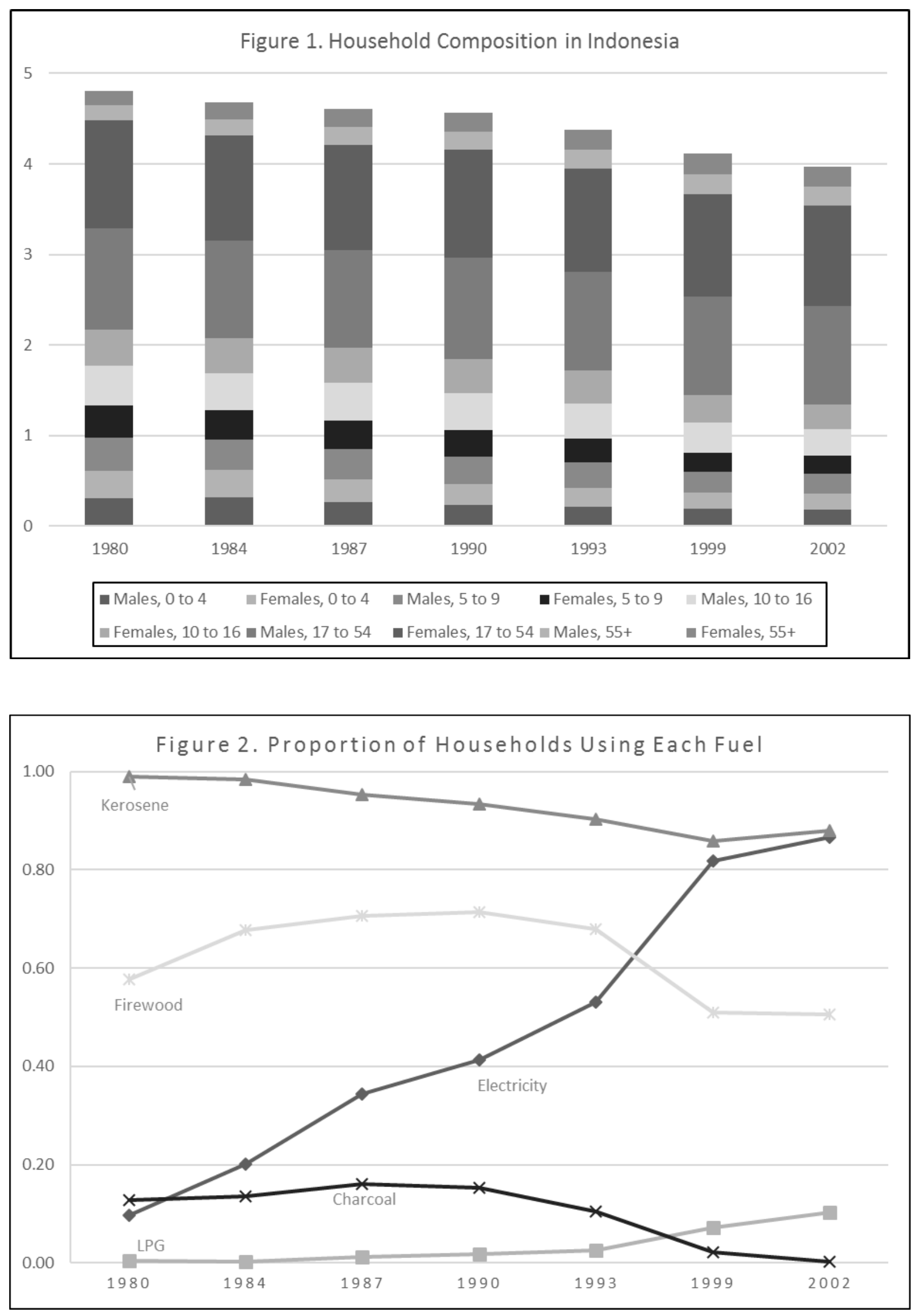
Figure 3. Sources of Change in Electricity Use

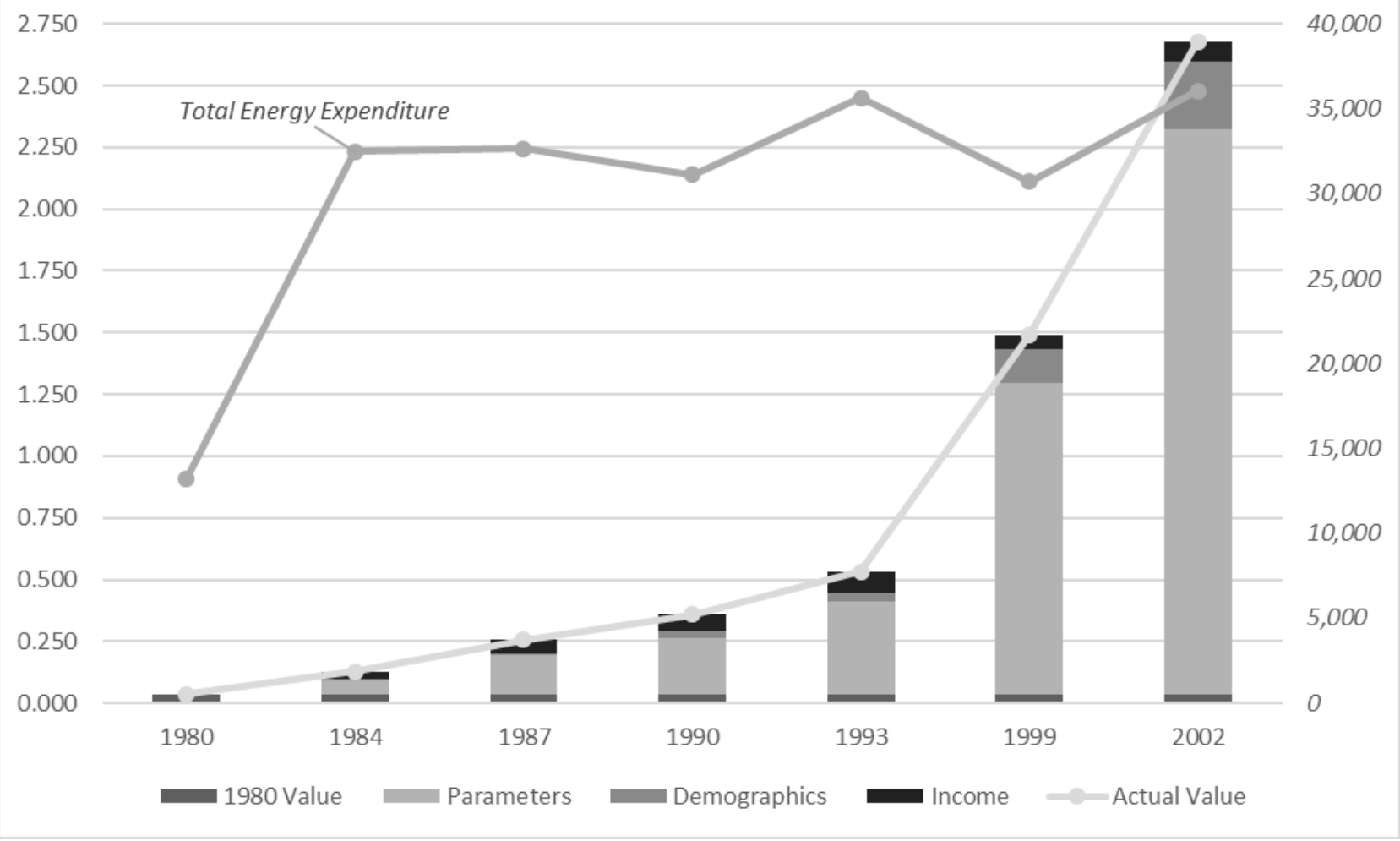

Figure 4. Sources of Change in LPG Use

0.275

0.250

0.225

0.200

0.175

0.150

0.125

0.100

0.075

0.050

Total Energy Expenditure

0.025

0.000
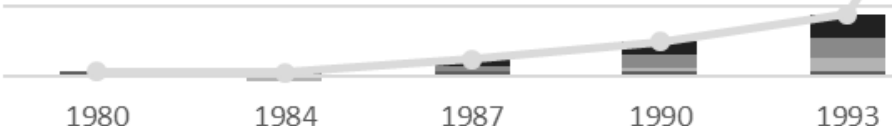

1990

1993
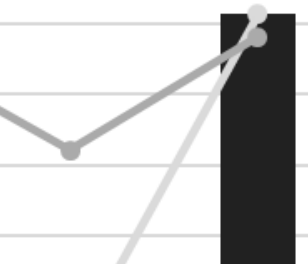

35,000

30,000

25,000

20,000

15,000

10,000

5,000

$-0.025$

1980 Value

Parameters

Demographics

Income $\longrightarrow$ Actual Value 

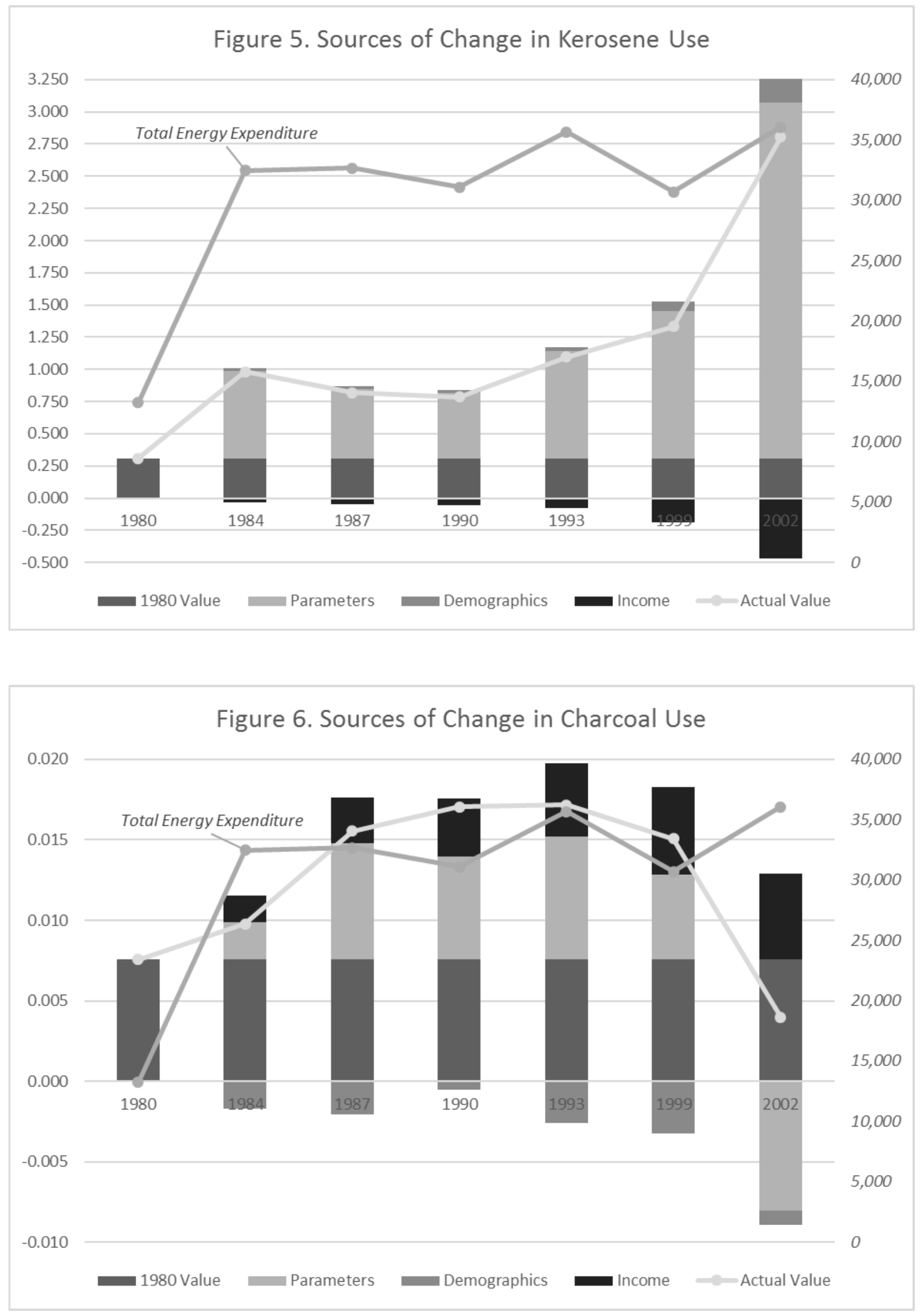


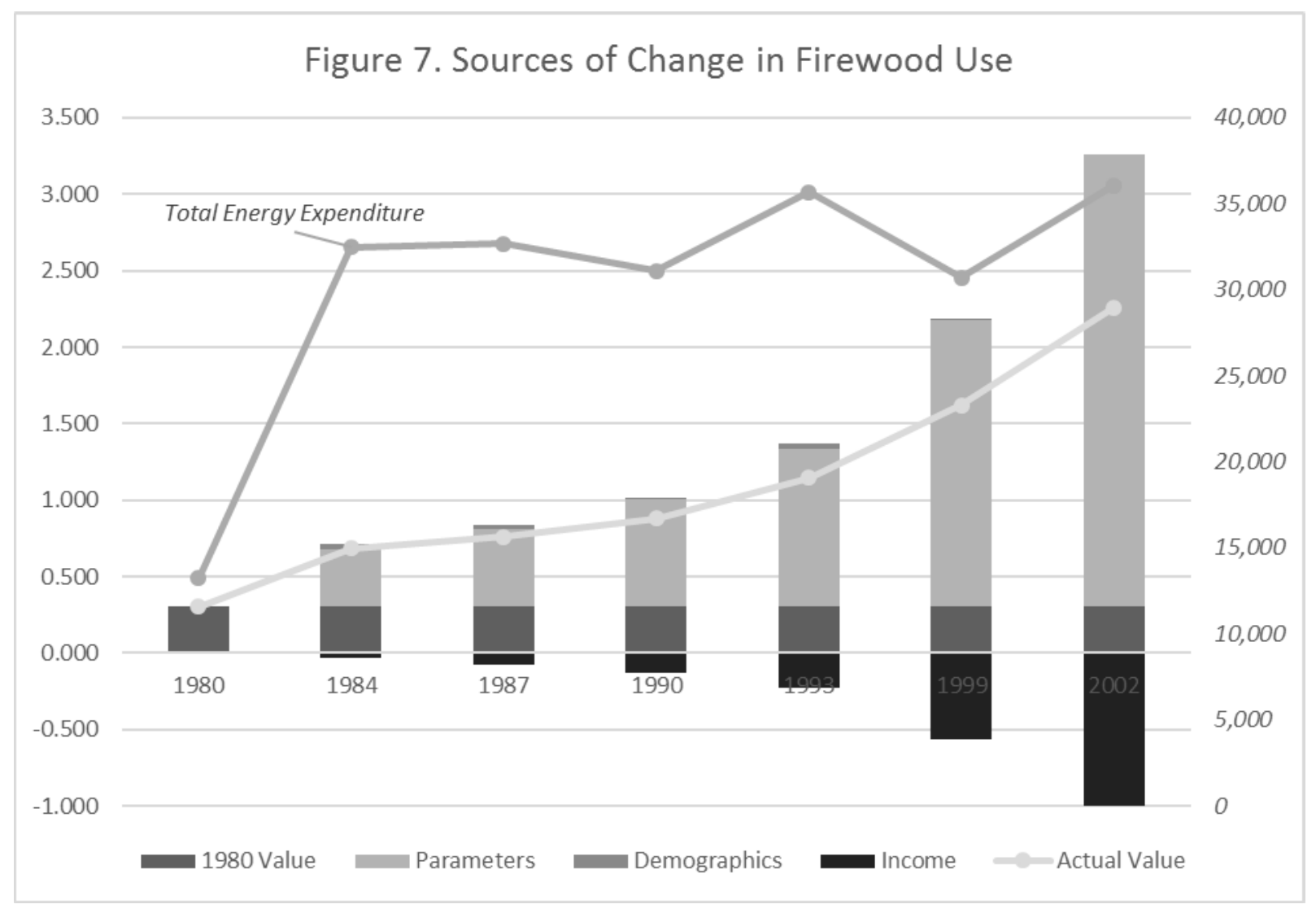


Table A1. Conversion Factors

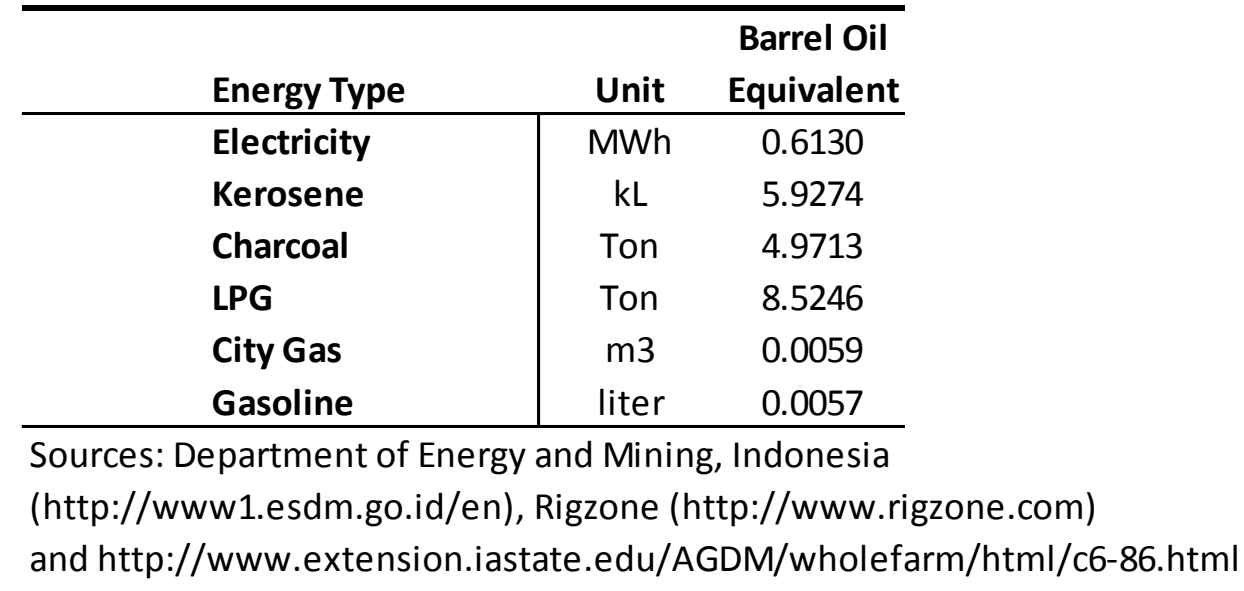


Table A2. Predicted Change in Fuel Expenditure as a Share of Total Monthly Household Expenditure

\begin{tabular}{|c|c|c|c|c|c|c|c|c|c|c|c|c|}
\hline & \multicolumn{6}{|c|}{ Electricity } & \multicolumn{6}{|c|}{ LPG } \\
\hline & 1984 & 1987 & 1990 & 1993 & 1999 & 2002 & 1984 & 1987 & 1990 & 1993 & 1999 & 2002 \\
\hline 1980 Value & 0.037752 & 0.037752 & 0.037752 & 0.037752 & 0.037752 & 0.037752 & 0.0015 & 0.0015 & 0.0015 & 0.0015 & 0.0015 & 0.0015 \\
\hline Parameters & 0.013032 & 0.093575 & 0.14325 & 0.260334 & 1.08396 & 1.957786 & -0.0015 & -0.0015 & -0.0015 & -0.0015 & -0.00131 & $-3.3 E-05$ \\
\hline Demographics & -0.02237 & -0.0198 & -0.01687 & -0.01582 & -0.00985 & -0.00383 & 0.000563 & 0.000466 & 0.00046 & 0.000392 & 0.000267 & 0.000417 \\
\hline Income & -0.01152 & -0.00418 & -0.00071 & 0.00663 & 0.021936 & 0.033792 & 0.001092 & 0.001399 & 0.001547 & 0.001869 & 0.002609 & 0.003279 \\
\hline Param*Dem & -0.05008 & -0.03604 & -0.01149 & 0.01833 & 0.252237 & 0.542205 & -0.00356 & -0.00347 & -0.00346 & -0.00339 & -0.00325 & -0.0025 \\
\hline Param*Inc & -0.03015 & 0.024061 & 0.03936 & 0.088378 & 0.031904 & 0.079629 & -0.00409 & -0.00439 & -0.00454 & -0.00481 & 0.01926 & 0.056635 \\
\hline Dem*Inc & -0.05102 & -0.04852 & -0.0453 & -0.04256 & -0.03058 & -0.01697 & -0.00351 & -0.00341 & -0.00331 & -0.00313 & -0.00259 & -0.00156 \\
\hline Triple & 0.203825 & 0.205909 & 0.208266 & 0.196252 & 0.13849 & 0.158349 & 0.009514 & 0.009412 & 0.009323 & 0.009173 & 0.015544 & 0.044459 \\
\hline $\begin{array}{l}\text { Error } \\
\quad \text { Indices }\end{array}$ & 0.038901 & 0.002611 & 0.003383 & -0.01562 & -0.034 & -0.10919 & 0.001249 & 0.006117 & 0.012124 & 0.022022 & 0.100321 & 0.151233 \\
\hline Parameters & 0.053823 & 0.157091 & 0.227733 & 0.373897 & 1.260862 & 2.28509 & -0.00174 & -0.00025 & 0.00165 & 0.004795 & 0.045314 & 0.092268 \\
\hline Demographics & 0.007987 & 0.007431 & 0.025284 & 0.032275 & 0.135812 & 0.275177 & 0.000613 & 0.002204 & 0.004221 & 0.007528 & 0.035968 & 0.06362 \\
\hline Income & 0.028802 & 0.053096 & 0.066864 & 0.089747 & 0.057428 & 0.081508 & 0.000877 & 0.002677 & 0.00477 & 0.008295 & 0.049565 & 0.096047 \\
\hline
\end{tabular}

\begin{tabular}{|c|c|c|c|c|c|c|c|c|c|c|c|c|}
\hline & \multicolumn{6}{|c|}{ Kerosene } & \multicolumn{6}{|c|}{ Charcoal } \\
\hline & 1984 & 1987 & 1990 & 1993 & 1999 & 2002 & 1984 & 1987 & 1990 & 1993 & 1999 & 2002 \\
\hline 1980 Value & 0.307356 & 0.307356 & 0.307356 & 0.307356 & 0.307356 & 0.307356 & 0.007568 & 0.007568 & 0.007568 & 0.007568 & 0.007568 & 0.007568 \\
\hline Parameters & 0.693739 & 0.55372 & 0.525249 & 0.849552 & 1.142508 & 2.806838 & 0.003189 & 0.007964 & 0.006625 & 0.007931 & 0.006343 & -0.00592 \\
\hline Demographics & 0.018123 & 0.021673 & 0.02408 & 0.026658 & 0.034974 & 0.057711 & 0.000209 & 0.000463 & 0.000825 & 0.000601 & 0.001338 & 0.002912 \\
\hline Income & -0.00971 & -0.0204 & -0.02495 & -0.03385 & -0.05027 & -0.06188 & 0.00258 & 0.003727 & 0.004202 & 0.005091 & 0.006522 & 0.007298 \\
\hline Param*Dem & -0.61888 & -0.60486 & -0.60471 & -0.5753 & -0.37027 & 0.07738 & -0.01521 & -0.01528 & -0.01505 & -0.01591 & -0.01775 & -0.01901 \\
\hline Param*Inc & -0.67386 & -0.65526 & -0.67021 & -0.68146 & -0.72077 & -1.03108 & -0.01316 & -0.01202 & -0.01358 & -0.01056 & -0.01079 & -0.01521 \\
\hline Dem*Inc & -0.62934 & -0.63184 & -0.63422 & -0.63757 & -0.64948 & -0.66249 & -0.01524 & -0.01553 & -0.01582 & -0.01628 & -0.01778 & -0.0187 \\
\hline Triple & 1.857014 & 1.85225 & 1.855241 & 1.850241 & 1.714959 & 1.381251 & 0.045337 & 0.044725 & 0.044609 & 0.044129 & 0.044754 & 0.045078 \\
\hline $\begin{array}{l}\text { Error } \\
\quad \text { Indices }\end{array}$ & 0.036224 & -0.0043 & 0.006902 & -0.01015 & -0.07478 & -0.07014 & -0.00548 & -0.00608 & -0.00233 & -0.0054 & -0.00514 & $-4.7 \mathrm{E}-05$ \\
\hline Parameters & 0.678449 & 0.539643 & 0.508507 & 0.834535 & 1.143718 & 2.767027 & 0.002285 & 0.007197 & 0.006406 & 0.007607 & 0.005278 & -0.00802 \\
\hline Demographics & 0.025095 & 0.019302 & 0.02533 & 0.033586 & 0.071828 & 0.202191 & -0.00173 & -0.00206 & -0.00051 & -0.00258 & -0.00322 & -0.00093 \\
\hline Income & -0.03023 & -0.04796 & -0.05645 & -0.08001 & -0.18867 & -0.47162 & 0.001666 & 0.002834 & 0.0036 & 0.004581 & 0.005441 & 0.005351 \\
\hline
\end{tabular}


Table A2 (cont.)

\begin{tabular}{lcccccc}
\hline & \multicolumn{6}{c}{ Firewood } \\
& 1984 & 1987 & 1990 & 1993 & \multicolumn{1}{c}{1999} & \multicolumn{1}{c}{2002} \\
\cline { 2 - 7 } 1980 Value & 0.30153 & 0.30153 & 0.30153 & 0.30153 & 0.30153 & 0.30153 \\
Parameters & 0.31115 & 0.484802 & 0.728546 & 1.139442 & 2.46393 & 4.107006 \\
Demographics & -0.08345 & -0.10356 & -0.11019 & -0.11614 & -0.14083 & -0.15559 \\
Income & -0.10037 & -0.11291 & -0.1184 & -0.12933 & -0.15012 & -0.16516 \\
Param*Dem & -0.53192 & -0.54893 & -0.55563 & -0.54927 & -0.86557 & -1.15652 \\
Param*Inc & -0.62238 & -0.71839 & -0.81506 & -1.05825 & -1.99443 & -3.10074 \\
Dem*Inc & -0.5281 & -0.52567 & -0.52428 & -0.5227 & -0.51501 & -0.50712 \\
Triple & 1.735357 & 1.73837 & 1.735637 & 1.709647 & 1.808373 & 1.801906 \\
Error & 0.202225 & 0.244659 & 0.239667 & 0.373028 & 0.713027 & 1.135518 \\
$\quad$ & & & & & & \\
Indices & & & & & \\
Parameters & 0.379861 & 0.51215 & 0.701636 & 1.029906 & 1.874399 & 2.95752 \\
Demographics & 0.032405 & 0.020148 & 0.00829 & 0.042094 & 0.009353 & -0.00826 \\
Income & -0.02975 & -0.07394 & -0.12963 & -0.22558 & -0.56437 & -0.98994 \\
\hline
\end{tabular}


Figure A1. Sources of Change in Electricity as a Share of Energy Budget
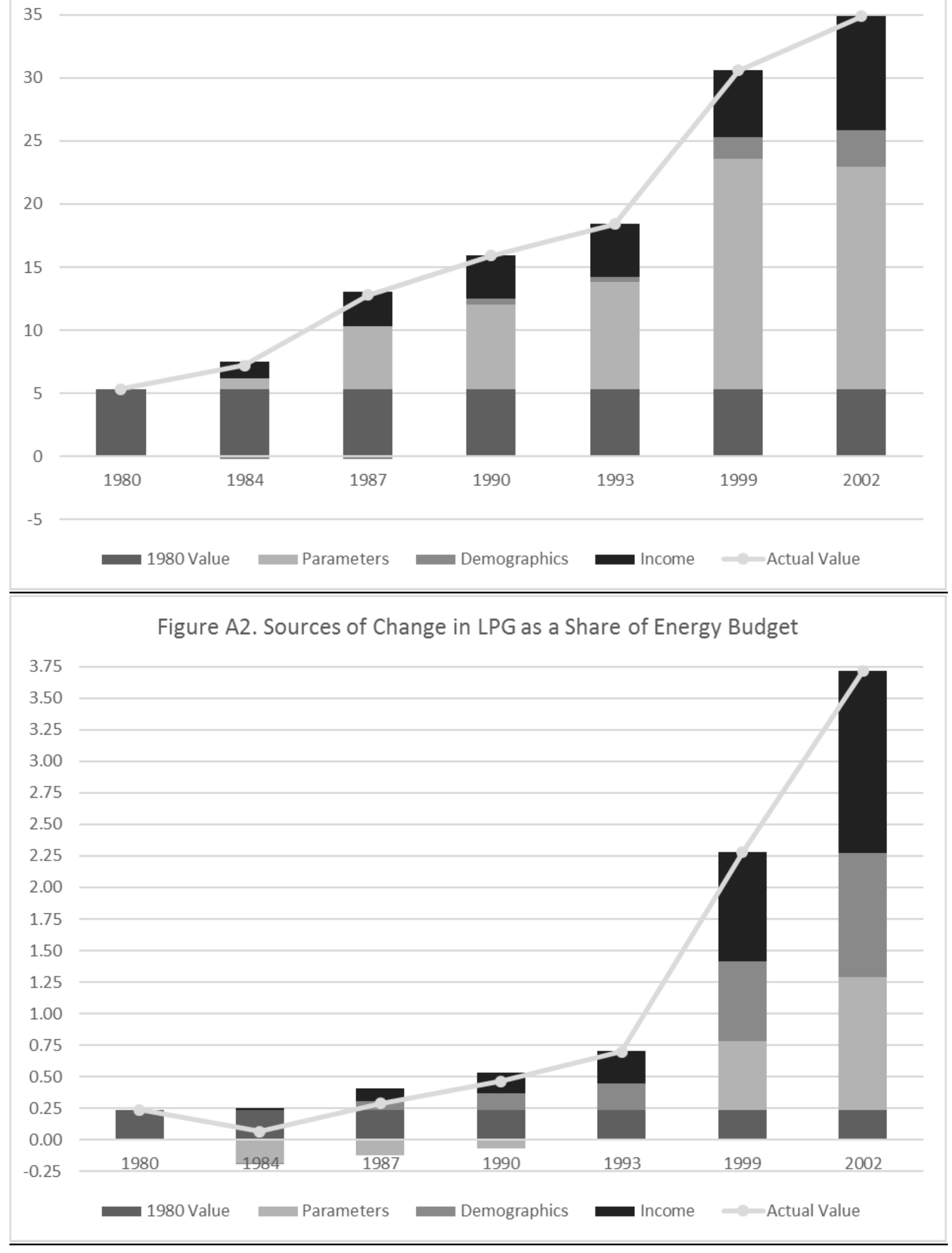
Figure A3. Sources of Change in Kerosene as a Share of Energy Budget

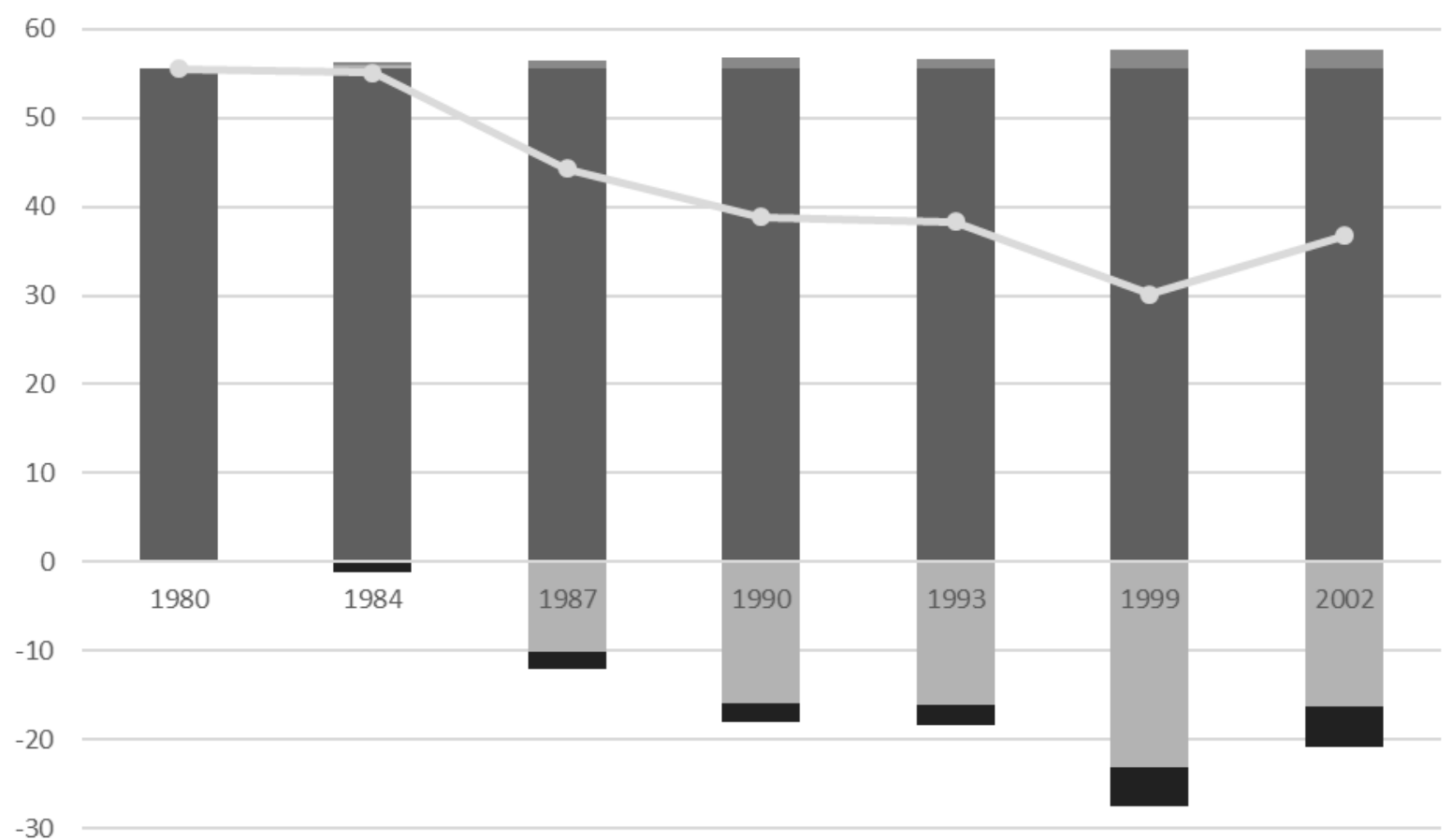

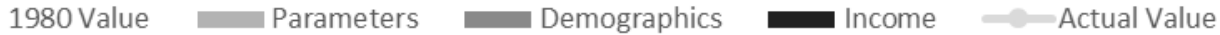

Figure A4. Sources of Change in Charcoal as a Share of Energy Budget

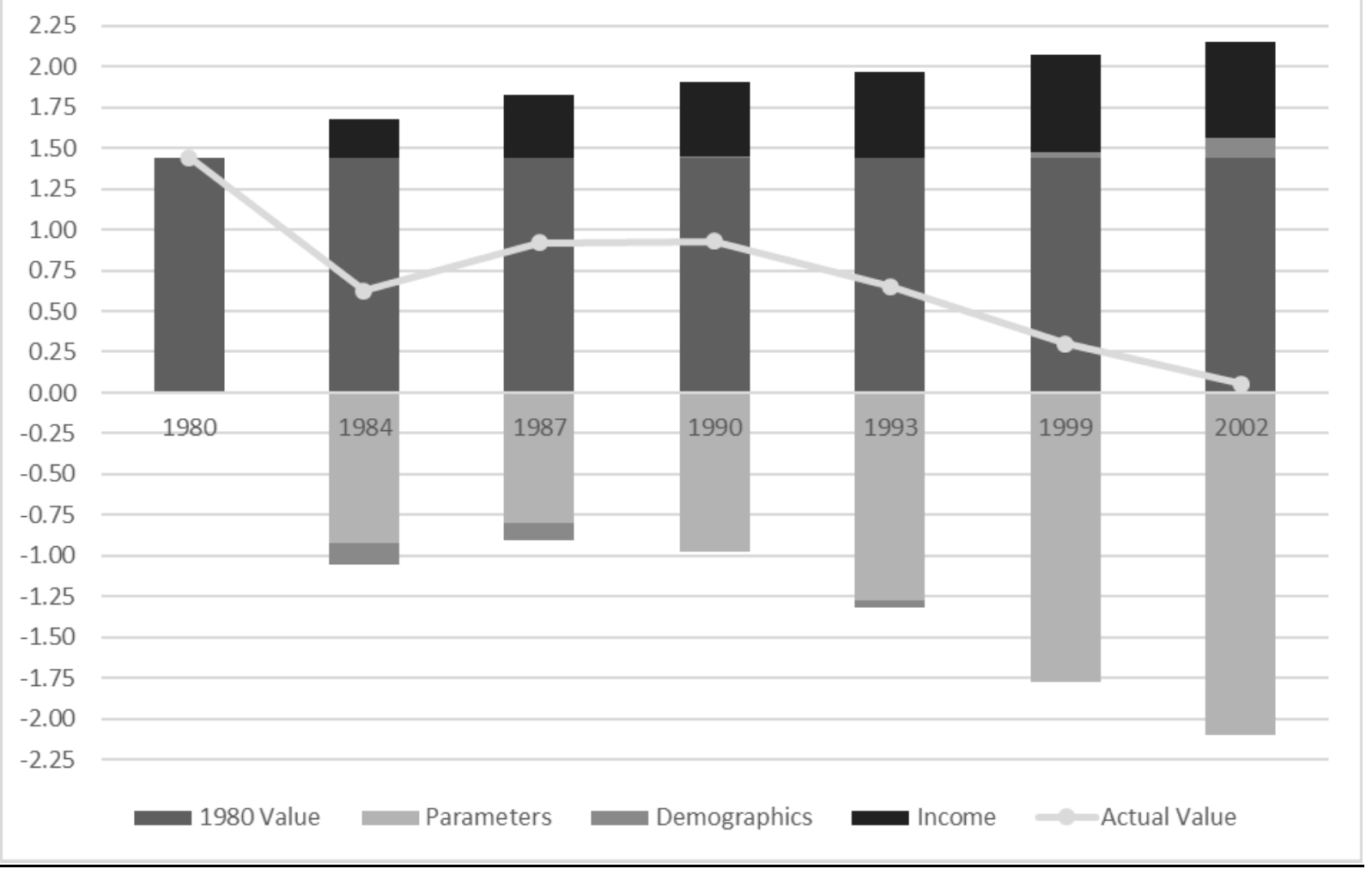




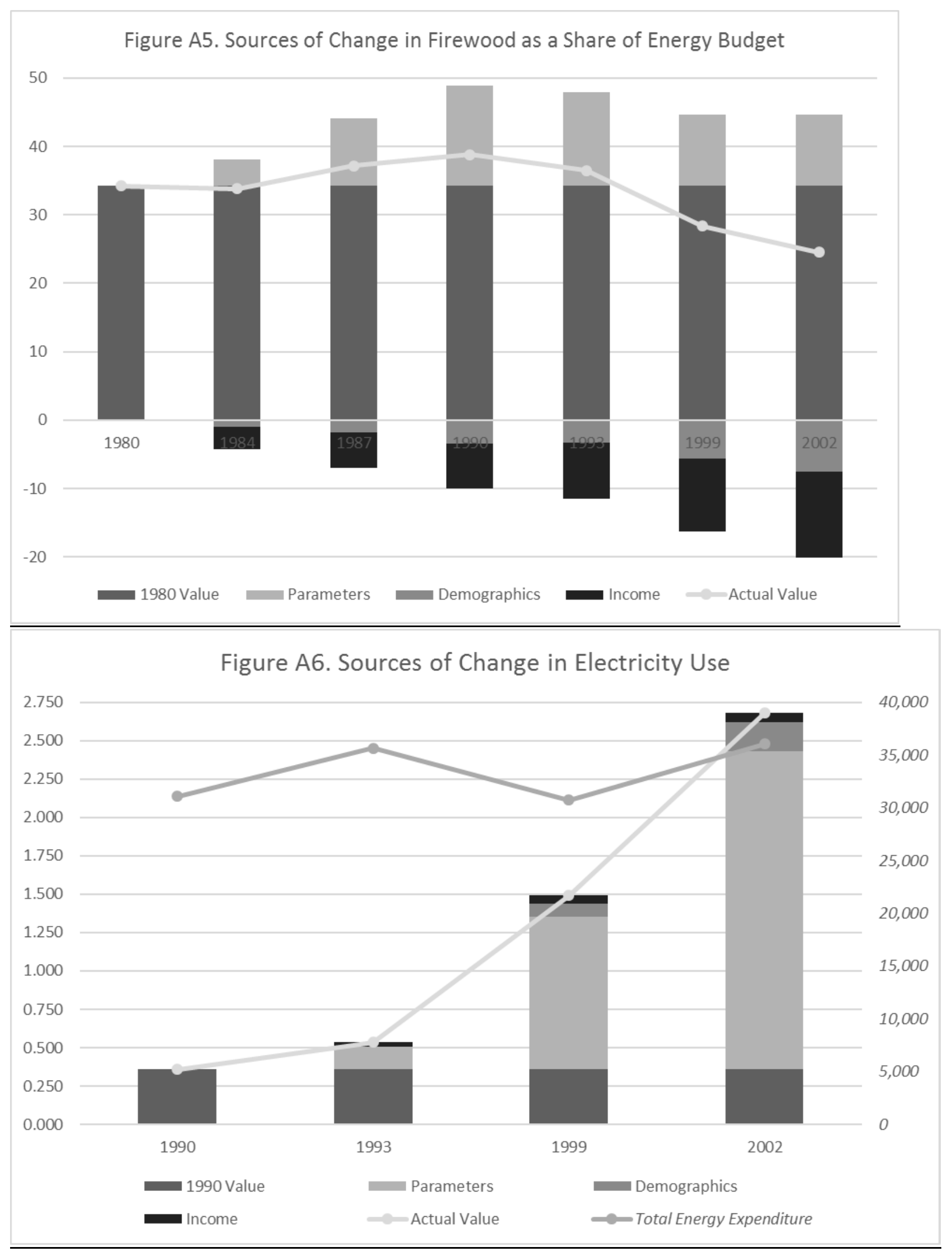


Figure A7. Sources of Change in LPG Use
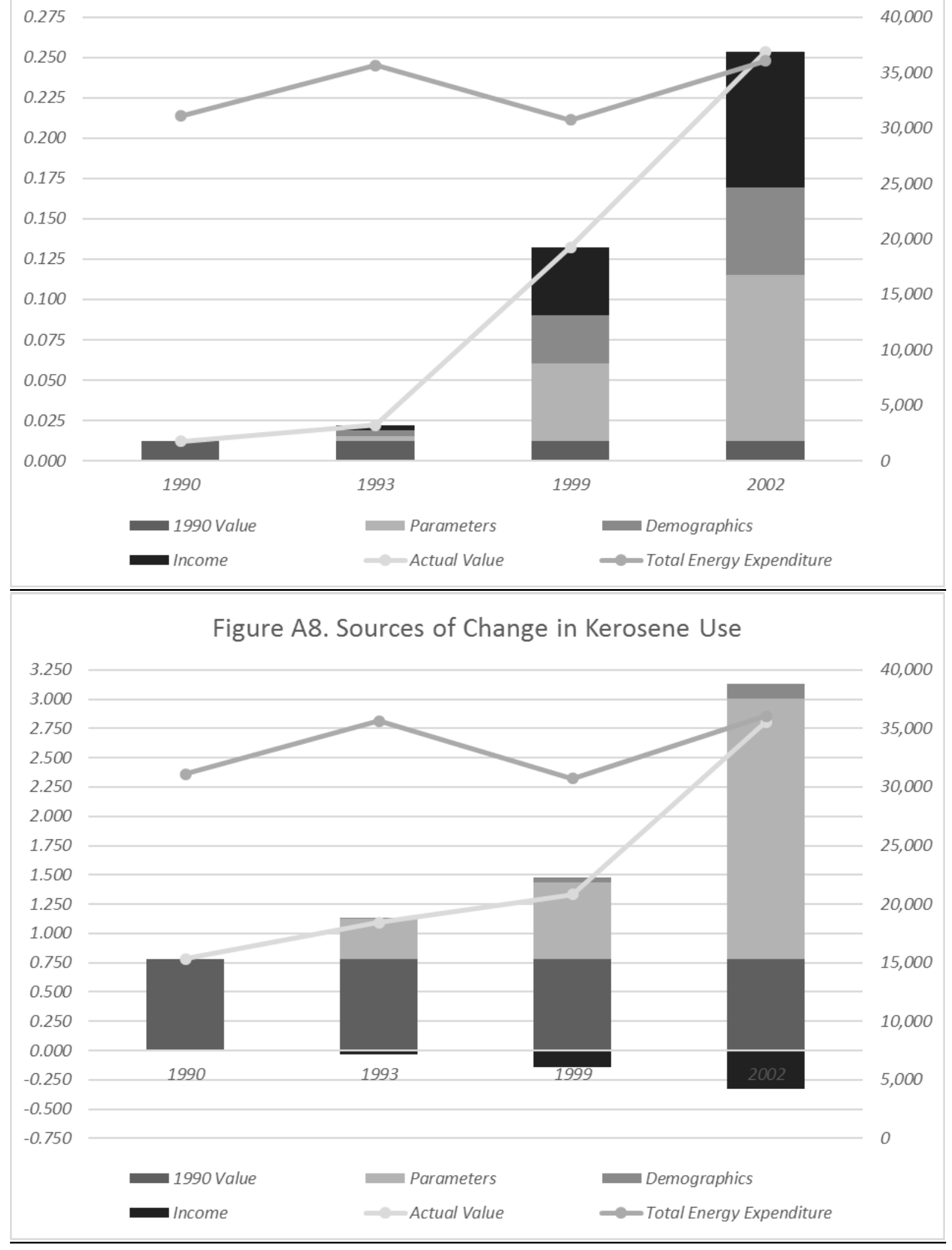


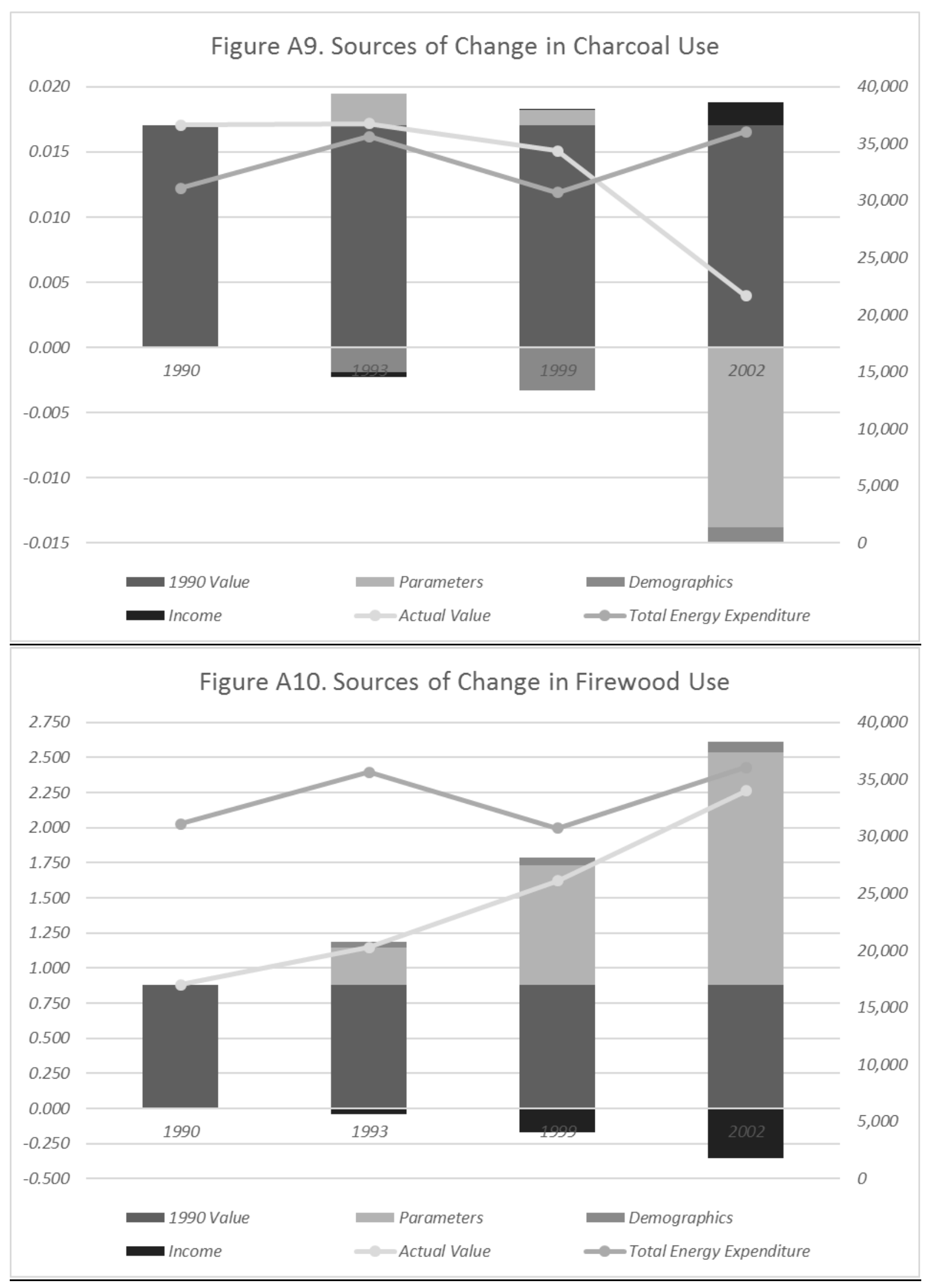




\section{Technical Appendix.}

The specification for our econometric analysis is:

$$
V_{i j t}=\beta_{i t}^{0} \ln \left(Y_{t}\right)+\beta_{i t}^{Y}\left[\ln \left(Y_{t}\right)\right]^{2}+\sum_{k} \beta_{i t}^{k} H_{t}^{k}+\sum_{m} \beta_{i t}^{m} C_{i j t}^{m}+\alpha_{i t}+\omega_{i j}+\varepsilon_{i j t}
$$

where $\beta_{i t}^{k}=\beta_{i t}^{k^{0}}+\beta_{i t}^{k^{Y}} \ln \left(Y_{t}\right)+\beta_{i t}^{k^{Y}} \ln \left(S_{t}\right)$ and $\beta_{i t}^{m}=\beta_{i t}^{m^{0}}+\beta_{i t}^{m^{Y}} \ln \left(Y_{t}\right)+\beta_{i t}^{m^{S}} \ln \left(S_{t}\right)$.

For ease of notation, denote the predicted values (latent budget shares) as (subscripts suppressed)

$$
\widehat{V}=\widehat{V}(Y, \boldsymbol{D}, \boldsymbol{B})
$$

where $Y$ continues to denote total real household expenditure per capita (income); $\boldsymbol{D}$ denotes the vector of demographic characteristics, including household-level characteristics $\left(H_{t}^{k}\right)$ and the distribution of the population across provinces; and $\boldsymbol{B}$ denotes a vector of structural parameters, including the estimated coefficients on all regressors $(\hat{\beta})$, the year fixed effects $(\hat{\alpha})$, the province fixed effects $(\widehat{\omega})$, and community characteristics $\left(C_{i j t}^{m}\right)$.

Then, the components of the decomposition are calculated as follows:

[1] Direct Effect of Income

[2] Direct Effect of Demographics

$$
\widehat{V}\left(Y_{t}, \boldsymbol{D}_{\mathbf{8 0}}, \boldsymbol{B}_{\mathbf{8 0}}\right)-V_{80}
$$

[3] Direct Effect of Parameters

$$
\widehat{V}\left(Y_{80}, \boldsymbol{D}_{\boldsymbol{t}}, \boldsymbol{B}_{\mathbf{8 0}}\right)-V_{80}
$$

$$
\widehat{V}\left(Y_{80}, \boldsymbol{D}_{\mathbf{8 0}}, \boldsymbol{B}_{\boldsymbol{t}}\right)-V_{80}
$$

[4] Interaction of Income and Demographics

$$
\widehat{V}\left(Y_{t}, \boldsymbol{D}_{t}, \boldsymbol{B}_{\mathbf{8 0}}\right)-V_{80}-\hat{V}\left(Y_{t}, \boldsymbol{D}_{\mathbf{8 0}}, \boldsymbol{B}_{\mathbf{8 0}}\right)-\hat{V}\left(Y_{80}, \boldsymbol{D}_{\boldsymbol{t}}, \boldsymbol{B}_{\mathbf{8 0}}\right)
$$

[5] Interaction of Income and Parameters

$$
\widehat{V}\left(Y_{t}, \boldsymbol{D}_{\mathbf{8 0}}, \boldsymbol{B}_{\boldsymbol{t}}\right)-V_{80}-\widehat{V}\left(Y_{t}, \boldsymbol{D}_{\mathbf{8 0}}, \boldsymbol{B}_{\mathbf{8 0}}\right)-\widehat{V}\left(Y_{80}, \boldsymbol{D}_{\mathbf{8 0}}, \boldsymbol{B}_{\boldsymbol{t}}\right)
$$

[6] Interaction of Demographics and Parameters

[7] Prediction Error

$$
\widehat{V}\left(Y_{t}, \boldsymbol{D}_{\boldsymbol{t}}, \boldsymbol{B}_{\boldsymbol{t}}\right)-V_{80}-\widehat{V}\left(Y_{80}, \boldsymbol{D}_{\boldsymbol{t}}, \boldsymbol{B}_{\mathbf{8 0}}\right)-\widehat{V}\left(Y_{80}, \boldsymbol{D}_{\mathbf{8 0}}, \boldsymbol{B}_{\boldsymbol{t}}\right)
$$

[8] Triple Interaction

$$
\widehat{V}\left(Y_{t}, \boldsymbol{D}_{t}, \boldsymbol{B}_{t}\right)-V_{t}
$$

$$
\widehat{V}\left(Y_{t}, \boldsymbol{D}_{\boldsymbol{t}}, \boldsymbol{B}_{\boldsymbol{t}}\right)-V_{80}-\sum[1]-[7]
$$

Following the "jointly created and equally distributed" principle of the revised Laspeyres index (Sun, 1998), we attribute one-half of each two-way interaction and one-third of the three-way interaction and the prediction error to its component factors as follows:

Income Index $=[1]+\frac{1}{2} \cdot[4]+\frac{1}{2} \cdot[5]+\frac{1}{3} \cdot\{[7]+[8]\}$

Demographics Index $=[2]+\frac{1}{2} \cdot[4]+\frac{1}{2} \cdot[6]+\frac{1}{3} \cdot\{[7]+[8]\}$

Parameters Index $=[3]+\frac{1}{2} \cdot[5]+\frac{1}{2} \cdot[6]+\frac{1}{3} \cdot\{[7]+[8]\}$ 